\title{
DYNAMIC POWDER CRYSTALLOGRAPHY WITH SYNCHROTRON X-RAY SOURCES*
}

\author{
JOHN B. PARISE $\$$ \\ CHiPR and Departments of Chemistry and of Geosciences, State University of New York, Stony Brook, N.Y. 11794-2100, U.S.A.
}

CHRISTOPHER L. CAHILL ${ }^{\text {II }}$

Department of Chemistry, State University of New York, Stony Brook, N.Y. 11794-2100, U.S.A.

YONGJAE LEE

CHiPR and Department of Geosciences, State University of New York, Stony Brook, N.Y. 11794- 2100, U.S.A.

\begin{abstract}
The increased brightness, tunability, low divergence and low emittance of X-ray beams available at synchrotron X-ray sources facilitate a variety of powder-diffraction experiments not practical using conventional in-house sources. Furthermore, the increased availability of fast position-sensitive detectors, along with implementation of improved software, make possible new classes of experiments. These include time-resolved powder-diffraction of phase transitions, precipitation, recrystallization and ion-exchange reactions. Examples of time-resolved studies that highlight some of these developments include: (1) observations of the phases forming during reaction under controlled hydrothermal conditions (e.g., FeS); (2) full Rietveld structure refinement using time-resolved data to determine the mechanism of ion exchange in zeolites. The advent of area detectors, commonly coupled with focusing optics at synchrotrons, will further increase the time resolution at the synchrotron, possibly leading to a data glut. Solutions are available now, and developments in the near term will allow semi-automatic decisions on which datasets to analyze amongst the thousands collected.
\end{abstract}

Keywords: synchrotron radiation, crystallography, time-resolved studies, diffraction, scattering, high pressure, element partitioning, phase diagrams, ion-exchange reactions, energy-dispersive diffraction.

\section{SOMMAIRE}

La luminance accrue, la possibilité de syntoniser, la faible divergence et le faible pouvoir émissif des faisceaux de rayons X disponibles aux sources synchrotron permettent une série d'expériences en diffraction X sur poudres qui ne sont pas du tout pratiques avec les sources conventionnelles. De plus, la disponibilité accrue de détecteurs efficaces sensibles à la position et de logiciels améliorés rend possible de nouvelles sortes d'expériences. Par exemple, il est maintenant possible d'étudier par diffraction X sur poudres le progrès dans le temps d'une transition de phases, une précipitation, une recristallisation, et une réaction d'échange ionique. Nous décrivons les exemples suivants pour souligner certains de ces développements: (1) observations des phases apparaissant au cours d'une réaction hydrothermale sous conditions controlées, impliquant par exemple FeS; (2) affinement complet d'une structure par la méthode de Rietveld en utilisant des données échelonnées dans le temps pour étudier le mécanisme d'échange ionique dans les zéolites. L'installation de détecteurs à aire, couplée en général avec une focalisation optique dans le circuit d'un synchrotron, augmenteront surement la résolution temporelle dans de telles expériences, menant nécessairement à un surplus de données. Nous avons déjà des solutions à ce problème, et des développements dans un futur rapproché permettront des décisions semi-automatiques à propos de quels prélèvements de données sont à retenir pour analyse, parmi les milliers qui sont enregistrés.

(Traduit par la Rédaction)

Mots-clés: rayonnement synchrotron, cristallographie, résolution temporelle, diffraction, dispersion, pression élevée, répartition des éléments, diagrammes de phase, échange d'ions, diffraction en dispersion d'énergie.

$\S \quad$ E-mail address: john.parise@ sunysb.edu

If Present address: Department of Civil Engineering and Geological Sciences, Notre Dame University, Notre Dame, Indiana 46556, U.S.A

* This contribution represents an outgrowth of a plenary address at the seventeenth General Meeting of the International Mineralogical Association in Toronto (1998). 


\section{INTRODUCTION}

In the past two decades, synchrotron X-rays have increased the sensitivity, accuracy and precision with which crystal structures can be determined (Coppens 1992, Cox 1992). Compared to conventional sealed-tube sources, synchrotron radiation is between $10^{4}$ and $10^{12}$ times brighter, and rather than having a sharply peaked spectrum, it generally has a broad spectral range caused by emission of photons as charged particles accelerate in a magnetic field. More recently, the use of undulators at synchrotron sources (Mochizuki et al. 1998, Shu et $a l$. 1995) has made possible greater manipulation of the spectrum produced. For monochromatic diffraction, the incident energy can be chosen using single-crystal monochromators. The radiation also has intrinsically small vertical divergence and can be focused both horizontally and vertically to image the source. This dramatic increase in brightness has made possible the study of the dynamics of chemical reactions (Bourgeois et al. 1996, Wulff et al. 1997, Yang et al. 1998) and yet maintains the possibility for routine study of diffraction from microcrystals and powders as a function of time; several excellent introductory texts on synchrotron X-radiation and crystallography are available (Baruchel 1993, Coppens 1992, Finger 1989, Kunz et al. 1997).

Some of the new experiments that will benefit from dynamic crystallographic studies include: (1) collection of data suitable for full determination of the structure of submicrometric single crystals (Neder et al. 1996a, b, c); (2) observation and interpretation of diffuse scattering from crystals of this size range (Neder et al. 1996b); (3) characterization of the structure of surfaces and surface-sorbate complexes; (4) collection of high-resolution powder-diffraction data suitable for structure determination; (5) phase identification from very small quantities of powder, such as might be obtained from products of weathering; (6) resonant X-ray-scattering studies of single crystals and powders to enhance contrast between structural features such as atom site-occupancy factors, and (7) simultaneous diffraction and spectroscopic information from small quantities of powder. Time-resolved crystallography will provide information for the interpretation of the mechanism of reaction and new insights on mineral reactivity. Points (1) - (7) above are the subject of recent reviews written with an emphasis of these developments on the Earth Sciences (Parise 1998) and solid-state and materials chemistry (Parise \& Chen 1997, Parise et al. 1998).

In this review, we concentrate on the hardware and software required to perform time-resolved diffraction experiments. The time, angular and spatial resolution required dictates the experimental set-up. For example, simply identifying the phases present is sufficient to follow reaction kinetics, identifies short-lived reactionintermediates, and elucidates the reaction pathway. On the other hand, determination of the reaction mechanism at an atomistic level requires more careful attention to the collection of monochromatic data, with the highest possible time-resolution and signal-to-noise discrimination, to allow full refinement of the structure using the Rietveld technique (Larson \& Von Dreele 1986, Rietveld 1969, Young 1995). Much of the hardware described can be used for home-laboratory experiments on powders and single crystals as well as for work at synchrotrons.

\section{EXPERIMENTAL EQUIPMENT FOR THE TIME-RESOLVED EXPERIMENT}

The experimental configuration, including the choice of radiation source, beamline optics, sample cell and software, is dependent on the system studied and the goal of the study. For example, if the goal is to determine the position of $\mathrm{H}$ or $\mathrm{Li}$ during discharge of a manganese-oxide-based battery material, then use of a neutron source is needed. Some of the choices outlined below are not exhaustive, but give some idea of the options available.

\section{$X$-ray sources}

The source characteristics best suited to time-resolved diffraction depend on the resolution required. If the reaction is slow and if moderate resolution can be tolerated, the home laboratory provides a convenient setup unlikely to be improved at remote synchrotron facilities. Although the highest time-resolution, for a given signal-to-noise discrimination, will be obtainable at a synchrotron source, valuable preliminary experiments can be done in the home laboratory (Atou \& Badding 1995). This development will continue as area detectors and focusing optics are incorporated with more powerful commercial X-ray sources. Some of the hardware developed in our laboratories have been designed with this in mind (Norby et al. 1998).

Because of its higher brightness (intensity/source size), the synchrotron source is increasingly applied to smaller samples. Recent work on microdiffractometry (Rindby et al. 1997) suggests that micrometer-sized Xray beams of unprecedented brilliance at third-generation sources can be used for single-crystal diffraction in either static (Neder et al. 1996a, b, c) or dynamic experiments (Bourgeois et al. 1996, Moffat \& Ren 1997, Wulff et al. 1997, Yang et al. 1998). Although singlecrystal investigations are ideal, the most widely used diffraction procedures are those applied to crystalline powders (Finger 1989, Klug \& Alexander 1974). At synchrotron sources, increased brightness is used to optimize angular (Cox 1992, Cox et al. 1988) or spatial resolution. In the latter case, diffraction from a smaller sample places increased demands on the quality of the powder averaging. In principle, increased brightness can also be used to increase the rate of data collection by several orders of magnitude; this is the basis for the time-resolved studies now being pursued at several 
facilities (Cahill et al. 1998a, 2000, O'Hare et al. 1998a, b, Parise et al. 1997, Svensson et al. 1997).

\section{Synchrotron-beamline configurations and detectors for powder diffractometry}

Some of the experimental configurations for monochromatic and energy-dispersion powder-diffraction at synchrotron sources are shown in Figure 1. The most important difference between powder-diffraction in the home-laboratory setting and at a synchrotron is the distance to the source and the 2-3 orders-of-magnitude lower divergence of the beam. Whereas early designs (Cox et al. 1988) operated successfully with unfocused beams, increases in sample-to-source distances, along with increased emphasis on microdiffraction and the use of environmental chambers, have led to the use of focused beams. Crystal optics or mirrors (Eng et al. 1995) at third-generation sources, such as the Advanced Photon Source (APS) in the USA, the European Synchrotron Radiation Facility (ESRF) in Grenoble, France and the Super Photon Ring (SPRing8) in Japan, are now routine equipment.

The highest angular resolution, $\Gamma<0.01^{\circ}$, in terms of full width at half maximum (FWHM), is afforded by the crystal-analyzer configuration (Cox 1992, Cox et al. 1988). This configuration effectively eliminates systematic errors due to sample shift and transparency (Cox et al. 1988, Klug \& Alexander 1974) prevalent in the Bragg-Brentano parafocusing geometry (Klug \& Alexander 1974). The decrease in integrated intensity dictates that this mode of operation is reserved for the most strongly crystalline of samples and for $a b$ initio determination of crystal structure from powder-diffraction data (Cox 1992). It is rarely applicable to time-resolved studies, which require an extended view of the powder-diffraction pattern. The high signal-to-noise discrimination afforded by this geometry is particularly useful for the detection of weak diffraction phenomena at low angles, which commonly are crucial for the determination of unit-cell parameters (Hriljac et al. 1991). Increased time-resolution, without compromising angular resolution, can be achieved by coupling several detectors and crystal analyzers to the same axis, so the pattern can be recorded in several segments simultaneously (Hodeau et al. 1998, Siddons et al. 1998, 1999, Toraya et al. 1996). For cylindrical samples, the production of a powder-diffraction pattern from these segments is straightforward, having been used in neutron powder-diffraction at reactor sources where intensity is also at a premium for some time. Because the angles between the normal to the plate and the incident and diffracted beam are not equal, use of the flat-plate sample holder requires corrections for sample illumination.

An increase in time resolution usually involves compromising angular resolution. Parallel-blade collimators (Fig. 1), especially when coupled with multiple detec- tors, can give moderate resolution, with angular acceptances of $0.03-0.07^{\circ}$ (Toraya et al. 1995) and high through-put. Receiving slits are particularly useful when samples are studied under non-ambient pressure and temperature, and it is desirable to exclude diffraction from sample-environment containers such as high-pressure cells, furnaces and cryostats.

Over the past decade, area detectors with a large dynamic range and capable of rapidly imaging large sections of reciprocal space have become the recorders of choice for single-crystal diffraction. They are increasingly being used for powder diffractometry (Hammersley et al. 1996) and provide a number of advantages (Thoms et al. 1998) over conventional detectors. As they record a large portion of the Debye-Scherrer ring, the effects of preferred orientation can be clearly observed. By changing the angle of inclination of the sample to the incident beam, intensity variations around the ring can be modeled to define its effects on sample texture (Hammersley et al. 1996, Larson \& Von Dreele 1986). Another advantage of recording a large portion of the ring is the better averaging attainable upon integration; the low divergence of the synchrotron X-ray beam places greater restrictions on the minimum particle-size acceptable for recording powder-diffraction data.

There are several disadvantages when area detectors are used without collimation, some of them due to the non-discriminating nature of both imaging plates (IP) and charge-coupled devices (CCD). The synchrotron beam inevitably excites fluorescence within the hutch, and care must be taken to shield these devices from stray radiation. These devices commonly lack slits, which decreases the signal-to-noise discrimination as scattering from sample containers or environmental chambers contaminates the pattern. Although such contamination can be eliminated using subtraction (Chen et al. 1996, 1997b), another possibility, when powder averaging is not a problem and angular resolution can be relaxed (to say $\Gamma=0.03^{\circ}$ ), is to use an energy-discriminating position-sensitive detector (PSD) fitted with a slit (Fig. 1). Whereas most commercial PSDs operate in the so-called "streaming mode", proportional counting and energy discrimination are possible with these devices. One such PSD is used at the X7A line of the National Synchrotron Light Source (NSLS) (Cox 1992, Cox \& Wilkinson 1994, Jephcoat et al. 1992, Smith 1991) and is particularly useful for small samples and for collection of data suitable for resonant-scattering studies.

Another concern with the use of area detectors is read-out time. When transient processes occur on a subsecond scale, the time required to read detectors after exposure is a severe limitation. Recent improvements in online imaging plate (IP) technology (Thoms et al. 1998) and CCD capabilities will improve this situation. One simple solution to this problem is to record the pattern continuously behind a slit and then process the data after the reaction is complete (Norby 1996, 1997b). 
The Translating Imaging Plate (TIP) detection system (Fig. 2) has largely fulfilled its original potential for the acquisition of high-quality monochromatic powder-dif- fraction data, allowing the study of time-resolved phenomena at high pressure (Chen et al. 1998, Parise et al. 1998). This system has allowed not only the elucidation

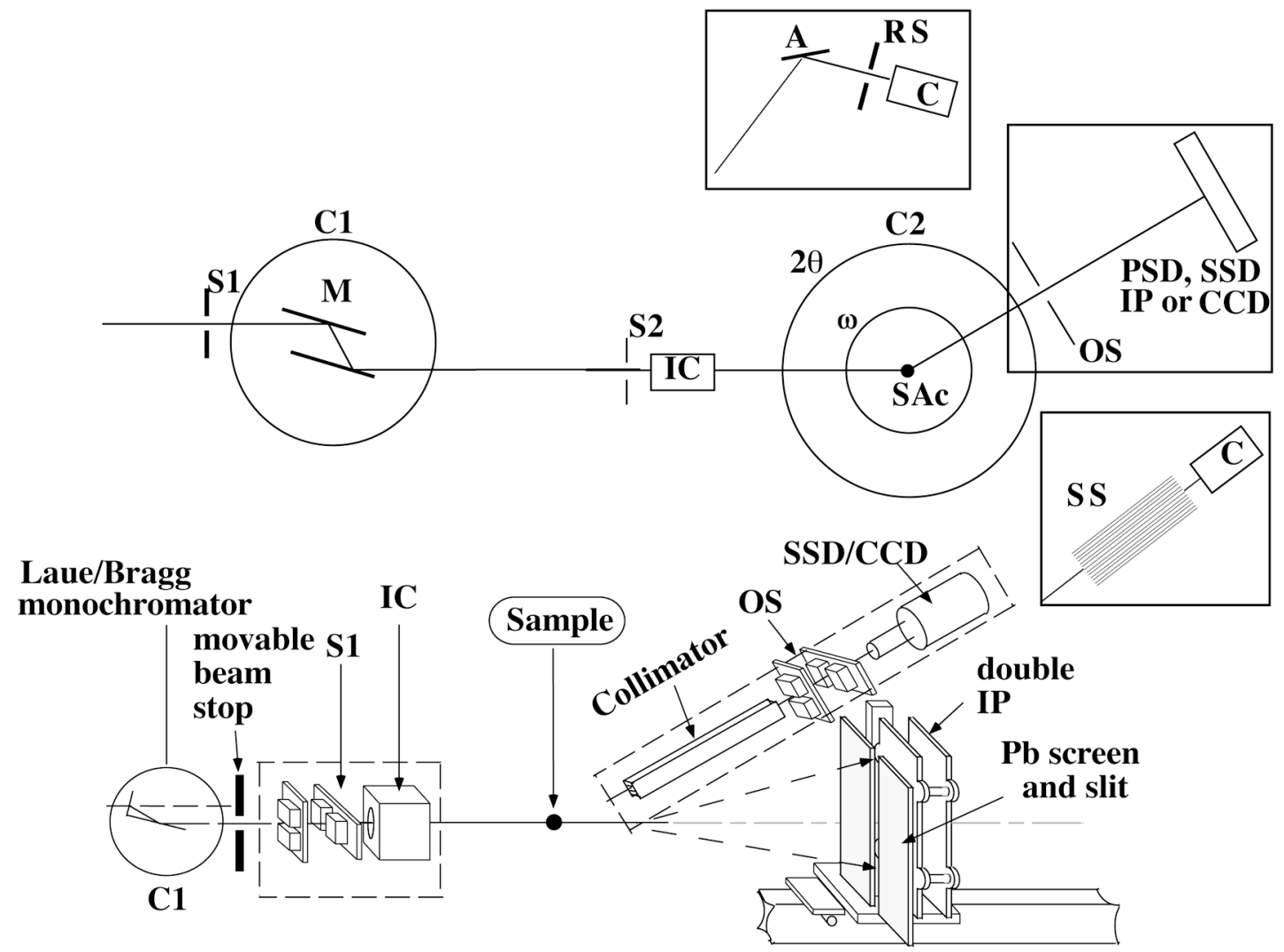

FIG. 1. One schematic design (top) for a beamline geometry suitable for time-resolved synchrotron powder diffractometry in monochromatic mode. A double-crystal monochromator (M), either channel cut or independently translatable and rotatable, is used to select the incident energy. A mirror or bent crystal optics (not shown) is commonly used to focus the beam on the sample. Because the synchrotron beam decays with time, an incident-beam monitor (IC) is needed to normalize data to the same relative-intensity scale. Two common sample geometries, flat plate (not shown) and capillary (SAc), are often combined with three detection schemes (shown in boxes): crystal-analyzer (A) mode (Cox 1992, Cox et al. 1988), vertical (Soller) slit (SS) assembly (both coupled to point counter, C) and detection with a position-sensitive detector (PSD) or area detector such as an imaging plate (IP) or charge-coupled device (CCD). In the case of the area detectors, it is difficult to use slits or an analyzer crystal (or both) to better define the scattering from the sample, and contamination from the sample assembly (see below) can be a problem. The resolution in this latter case is generally dominated by the diameter of SAc or area detectors such as an IP or CCD detectors (Hammersley et al. 1996). The symbols have the following meaning: $\underline{\mathbf{S 1}}, \underline{\mathbf{S 2}}$ : slits; $\underline{\mathbf{C 1}}, \underline{\mathbf{C 2}}$ : circles, mono and sample/counter; $\underline{\mathbf{M}}$ : single-crystal monochromator (Si, Ge); IC: ionization chamber; $\underline{\mathbf{S A c}}$ : sample (capillary); $\underline{\mathbf{O S}}$ and $\underline{\mathbf{S S}}$ : optional slit for area or PSD detectors or Soller slit for scintillation counter; A: optional crystal analyzer; $\underline{\text { PSD: }}$ : position-sensitive detector; $\underline{\mathbf{C C D}}$ : charge-coupled device detector; $\underline{\mathbf{I P}}$ : imaging plate detector. A typical experiment using the IP detector at the X17B1 beamline of the NSLS (http://www.nsls.bnl.gov) is shown at bottom. This beamline operates in monochromatic mode, typically with $\mathrm{E}>35 \mathrm{keV}$, or is configured for white-beam operation by removing the monochromator. Key components of the installation for monochromatic X-ray scattering studies are: (1) the Laue-Bragg monochromator, which allows conversion from energy-dispersion diffraction mode using a solid-state detector (SSD) to monochromatic diffraction using two-theta scans of the SSD; (2) a movable beamstop allows easy conversion from monochromatic to white beam in less than $60 \mathrm{~s}$; (3) a double-plate IP holder, allowing determination of the IP-to-sample distance with a single exposure and continuous monitoring of this distance throughout the experiment; (4) a lead screen with an adjustable slit installed before the plates, which can be translated behind it. The exposed plate will give a complete record of a sample undergoing a phase transition (see Figs. 5, 6 and 8, for example). 


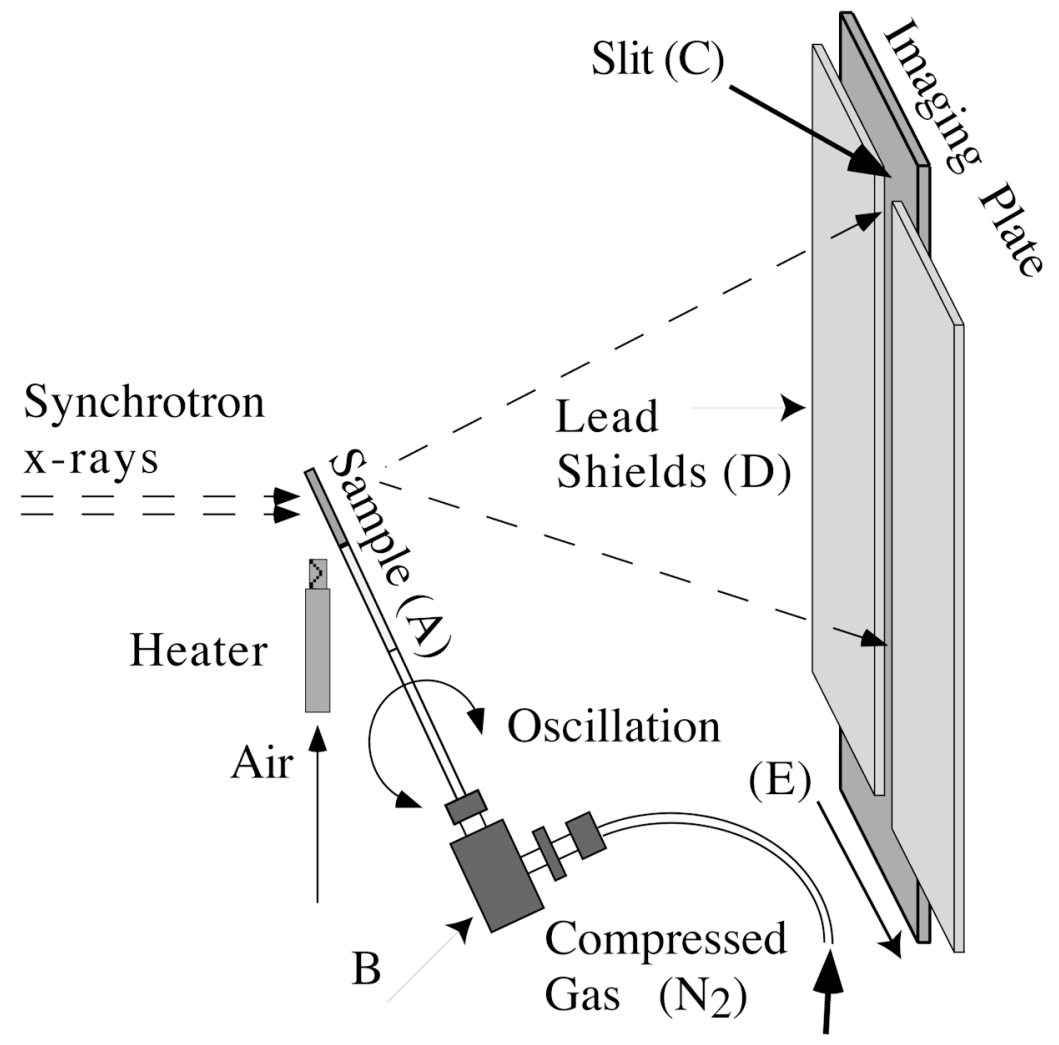

FIG. 2. The capillary reaction cell and translating imaging-plate detection system, as used at the NSLS. See text for details.

of phase transitions, but also the refinement of crystal structures, thereby allowing the transition to be followed at an atomistic level. A TIP, however, has a limited range of translation and requires real-time feedback to provide a trigger to activate the plate at a time appropriate to capture the transition. Ideally, this would be done without resorting to guesswork or to several loadings of the sample cell (Fig. 2). Coupling a CCD detector to the TIP can provide this feedback. Such a device has been installed and tested on the large-volume DIA apparatus (SAM-85) at the X17 beamline at the NSLS (Fig. 1).

The highest possible time-resolution is afforded with energy-dispersion diffraction. As diffraction from all $d$ values are recorded simultaneously, the time-resolution is determined by the brightness of the beam and the read-out time of the multichannel analyzer. Quantitative interpretation of the crystal structure is hampered by such systematic errors as energy-dependent absorption corrections, absorption edges and definition of the intensity versus energy curve. Reliable results have been obtained, however, and the software and methods to enable structure refinement using the Rietveld method are now well established (Chen \& Weidner 1997, Zhao et al. 1997). Energy-dispersion X-ray diffraction does have distinct advantages. The experiment allows for straightforward collimation and data collection at fixed angles, which makes it easier to discriminate against parasitic scattering from sample containers.

In general, for phase identification and determination of unit-cell parameters, energy-dispersion X-raydiffraction data are suitable and offer distinct advantages in terms of spatial and time resolution. In those cases where accurate determination of structural parameters is the objective, monochromatic data are preferred. Many beamlines are capable of changing between these two modes of operation, and a description of such a setup is given in two recent reviews (Parise \& Chen 1997, Parise et al. 1998).

\section{Sample containers and cells}

High-pressure apparatus: Because of the penetrating nature of high-energy X-rays, laboratory-scale synthesis apparatus is commonly transferable directly to the 


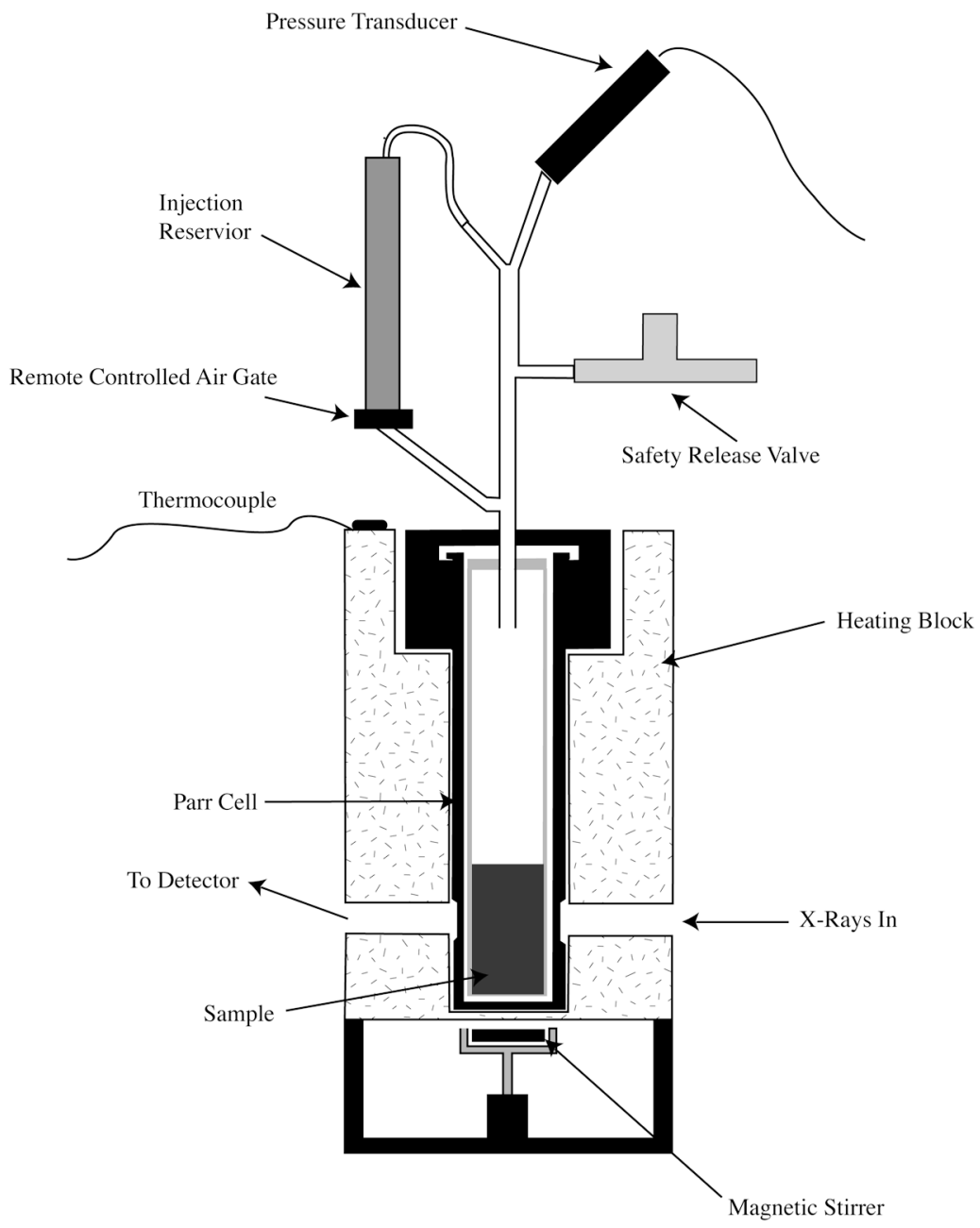

FIG. 3. The hydrothermal autoclave-type reaction cell, shown as used at the Advanced Photon Source (APS) (Evans et al. 1994). Walls are milled down to allow X-ray transmission while permitting a maximum operating temperature of $\sim 300^{\circ} \mathrm{C}$. The figure was modified after Shaw et al. (1998, 2000a).

synchrotron or requires only simple modification. For example, the large-volume high-pressure device originally designed for diamond growth (DIA) has been successfully interfaced to a synchrotron in Japan (Shimomura et al. 1985) at the Photon Factory and Spring8. Other installations followed in the USA (Weidner \& Mao 1993) at the NSLS and APS, and at DESY in Germany. All are now engaged in the study of materials at high pressure and temperature, using mainly energy-dispersion diffraction. Whereas this mode of operation has been used to determine the time-dependent partitioning of $\mathrm{Fe}$ in a mixture of olivine and $\beta$ phase of $(\mathrm{Fe}, \mathrm{Mg})_{2} \mathrm{SiO}_{4}$ (Chen \& Weidner 1997), the finer details of the partitioning in olivine were deduced from monochromatic data (Chen et al. 1996). By adding a TIP (Chen et al. 1996, 1997a, b), considerably better time-resolution was possible, and the mechanism of the transformation from olivine structure to the spinel structure was observed as a function of time (Chen $e t$ al. 1998). Other sample cells, such as furnaces and diamond-anvil cells, are also easily transferred. Similarly, steel hydrothermal-reaction vessels can be transferred from the laboratory to the synchrotron.

Hydrothermal autoclave-type cell: The cell shown in Figure 3 was introduced by Evans et al. (1994) and has been used extensively in many studies (Francis \& 
O'Hare 1998, Francis et al. 1996). The cell consists of a modified Parr reaction vessel $(25 \mathrm{~mL})$ with a section of its wall milled down to a thickness of $0.4 \mathrm{~mm}$. This thinner portion of the wall permits transmission of white Xradiation and has a maximum operating temperature of $230^{\circ} \mathrm{C}$. Higher operating temperature is possible in thicker-walled cells that require the focused optics at a third-generation source (Shaw et al. 1998, 2000a, b). Attached to the top of the cell is a head consisting of a pressure transducer, a safety-relief valve and an injection reservoir $(2 \mathrm{~mL})$. This reservoir consists of a remotely controlled gate valve that permits injection of a second solution into the cell at controlled time and temperature conditions. Temperature control of the cell is done via a resistance-heated aluminum block and is monitored with K-type thermocouples in contact with the outside of the reaction vessel.

Capillary-type cell: This sample cell (Fig. 2) was introduced by Norby $(1996,1997$ a) and has been widely used (Andersen et al. 1998, Artioli et al. 1996, Cahill et al. 1998b, Christensen et al. 1998, Cruciani et al. 1997, Grey et al. 1997, Gualtieri et al. 1997, Jensen et al. 1998, Ståhl et al. 1996). A general description follows. Samples are contained in a quartz capillary (A) that is closed at one end. The capillary is held in place with a Swagelock ${ }^{\circledR}$ (B) fitting mounted on a modified goniometer head. Hydrothermal conditions are created via an air heater and an overpressure of $\mathrm{N}_{2}$ gas applied to the closed end of the capillary. Diffracted X-rays are collected on a portion (C) of an IP detector, which is defined by two lead shields (D). The IP is translated (arrow E) to expose fresh portions of the plate and obtain diffraction data as a function of time. At the conclusion of a run, the exposed plates are read on a Fuji BAS2000 scanner, and the data are extracted using IDL routines; IDL is a registered trademark of Research Systems, Inc. 2995 Wilderness Place, Boulder, Colorado 80301, USA. Time resolution in this configuration is 5 minutes or less.

Small Environmental Cell for Real-Time Studies (SECReTS): It became clear in our early investigations that we needed a cell that could be used in both the home laboratory and at the synchrotron (Norby et al. 1998). This new cell was intended to be versatile, portable and to allow bench tests at home. Described here is the development of a micro-scale reaction cell for in situ powder-diffraction studies that can be used for hydrothermal titration, ion exchange, hydrothermal precipitation reactions and to investigate solid-gas phase interactions as a function of time.

The design of the reaction cell is shown in Figure 4. Reactions take place in a 1-mm quartz capillary (A) mounted in a Swagelock ${ }^{\circledR}$ tee (B) using a Vespel ${ }^{\circledR}$ ferrule. Through the connected tube $(\mathrm{C})$, a pressure can be applied to the surface of the reaction mixture in the capillary. Injection takes place through a $0.3-\mathrm{mm}$ quartz capillary (A) that goes through the tee and into the 1$\mathrm{mm}$ capillary. This $0.3-\mathrm{mm}$ capillary is mounted between a Swagelock ${ }^{\circledR}$ elbow and the tee with Vespel $^{\circledR}$ ferrules, all of which are mounted on a modified goniometer head (E). Injection under pressure through the elbow (A) is possible via a gas-chromatography syringe (not shown) mounted in an aluminum holder. A screw connected to the piston of the syringe ensures pressurization. By turning the screw, the piston is depressed, and a controlled volume can be injected into the 1-mm capillary through the $0.3-\mathrm{mm}$ capillary. Alternatively, the position of the sample capillary (A) can be plugged, and the assembly can be extended to expose the injection capillary location to the X-ray beam. Ports (D) and (C) then become supply and exhaust lines, respectively, for flow-through ion-exchange experiments or solid-gas phase reactions. This alternative configuration is described further in the ion-exchange examples discussed below.

\section{Software: data analysis and data glut}

Collection of either energy-dispersion or monochromatic data with ever-increasing time-resolution, as is envisioned at third-generation sources, will lead inevitably to a data glut. Whereas visual inspection, to identify the appearance of one phase or the disappearance of another, may be sufficient in some studies, it is desirable to develop an unbiased method that can be automated to provide real-time feedback on the course of a reaction. Such a method might provide information on systematic errors as well as on the appearance of new phases and the disappearance of others. It should also provide visual queues to allow the choice of a manageable number (3-5) of diffraction patterns to analyze, out of the hundreds collected. Our second example of in situ XRD investigations, ion exchange in zeolites, is discussed below and uses Iterative Target Transform Factor Analysis (ITTFA) (Liang et al. 1996), an unbiased mathematical treatment of the diffraction data that looks for changes as a function of time. From this processing, kinetic information and clues as to which patterns to use first for Rietveld refinement were obtained. Similar strategies will be important for efficient management of the ever-increasing quantities of data provided by bright X-ray sources.

\section{EXAMPLES OF TIME-RESOLVED IN SITU X-RAY-DifFraction StUdies}

Of the many time-resolved diffraction studies appearing in the literature, two examples will serve to demonstrate the complementarity of monochromatic X-ray powder-diffraction both as a chemical and a structural probe. The first, a study of the transformation of mackinawite $(\mathrm{FeS})$ to pyrite $\left(\mathrm{FeS}_{2}\right)$, uses monochromatic powder-diffraction to identify which phases appear during the course of a hydrothermal reaction under aerobic or anaerobic conditions. In this investigation, it is important to follow the reaction without interruption for sampling and without necessarily collecting data 
(a)

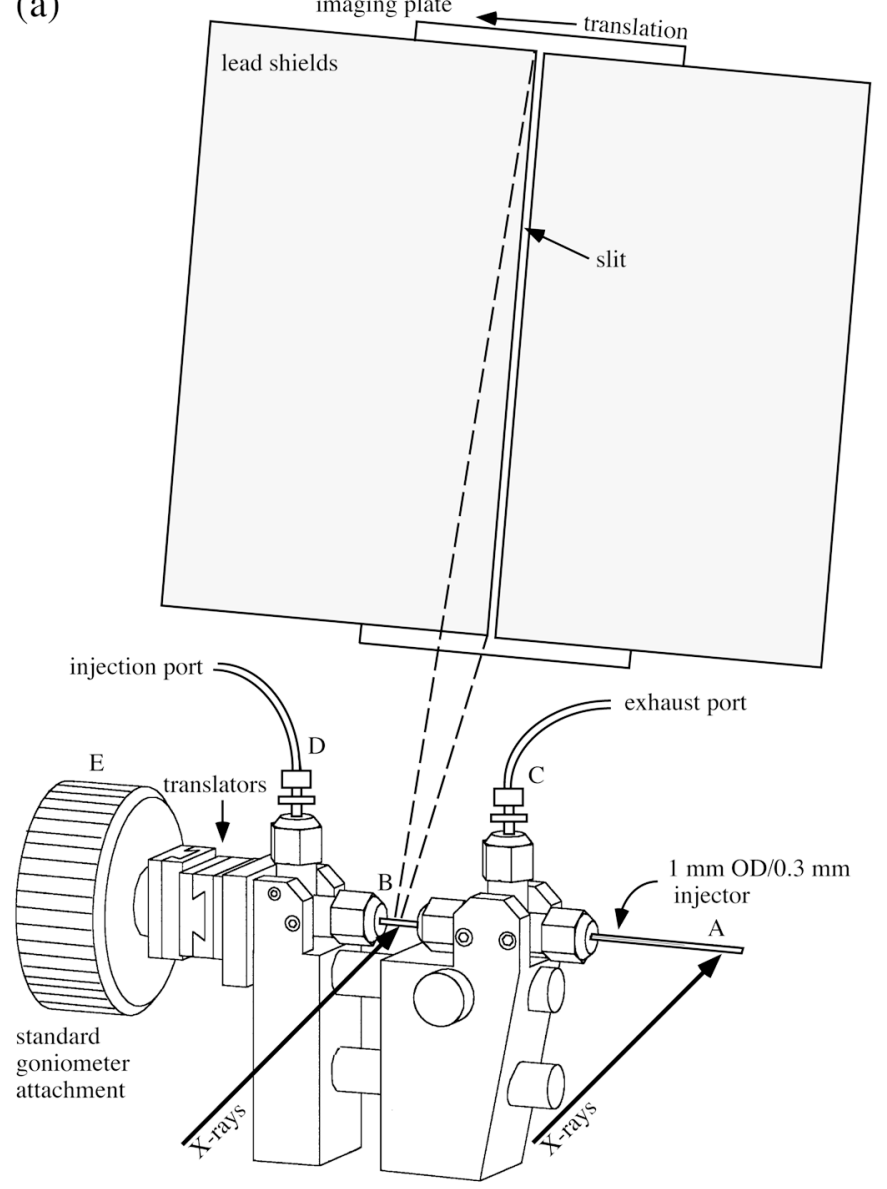

(b)

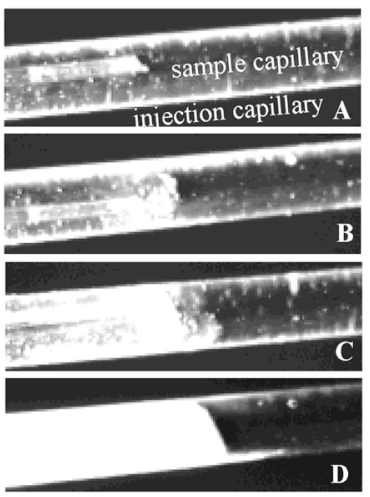

FIG. 4. View of the translating imaging plate (TIP) and the Small Environmental Cell for Real-Time Studies (SECReTS). Several modes of operation are possible with simple adjustments to the position of the X-ray beam on sample positions at $\mathbf{A}$ and $\mathbf{B}$ and the injection and exhaust ports at $\mathbf{C}$ and $\mathbf{D}$. Liquids or gases can be introduced through port $\mathbf{C}$, for example, by injection through a syringe or continuous flow for ion-exchange experiments. The device can be attached to a diffractometer through standard-fitting $\mathbf{E}$. Either position $\mathbf{A}$ or $\mathbf{B}$ can be heated to a maximum of $250^{\circ} \mathrm{C}$ using an air heater, or up to $1000^{\circ} \mathrm{C}$ with the sample at $\mathbf{A}$, using either a horseshoe heater or a tube furnace. The latter can be used for in situ dehydration studies under vacuum through port $\mathbf{D}$, or a mixture of vacuum and various atmospheres by manipulating ports $\mathbf{C}$ and $\mathbf{D}$. Another scenario is explained in (b), where the injection of a reactant is tested. Yet another example would have port $\mathbf{A}$ blocked off and sample-position B irradiated while solution or gas is passed over the sample, either heated by air flow or cooled to liquidnitrogen temperature using a cryostream device. There is sufficient optical access, and the device has been used with PSDs and CCD detector as well as IPs. Where optical access is not important, and pressure above the burst pressure of quartz glass is required (say, 20-25 atm.), steel tubing up to $\Phi=3 \mathrm{~mm}$ can be used at sample positions $\mathbf{A}$ or $\mathbf{B}$. Finally, the assembly can slide to accommodate capillaries of various lengths. The design will continue to evolve as more experiments are done by a variety of users at both the NSLS and the APS. (b) A trial at the X7B beamline at the NSLS with SECReTS to test the effectiveness with which the device can be used for injection under hydrothermal conditions. A quartz capillary, $\Phi=1.0 \mathrm{~mm}$, was filled with a saturated solution of $\mathrm{Na}_{2} \mathrm{SO}_{4}$ and heated to $60^{\circ} \mathrm{C}$. A saturated solution of $\mathrm{BaCl}_{2}$ was injected through a capillary, $\Phi=0.2 \mathrm{~mm}$ (frame A). While a TIP recorded the crystallization, the precipitate is seen forming in the video frames $\mathbf{B}, \mathbf{C}, \mathbf{D}$. In future, better synchronization between video or light-scattering information and the TIP will allow more precise determination of the time relation between precipitation, nucleation, grain growth, phase formation and transformation to other phases. This information will be useful for application to aluminosilicate zeolites and clays, and processes involving crystallization from gels. 
suitable for full structure (Rietveld) refinement. Rather, phase identification and thus reaction sequence permit deduction of the reaction mechanism. The second example involves determination of the ion-exchange mechanism in a faujasitic zeolite. This case illustrates the importance of having good static data in order to compensate for the poorer statistics available from monochromatic time-resolved data. It also serves to show the power of the Rietveld method (Larson \& Von Dreele 1986, Rietveld 1969, Young 1995), in combination with the constraints obtained from static studies, to provide data suitable for elucidation of the reaction mechanism.

\section{Precipitation and transformation of iron sulfides under reducing hydrothermal conditions}

The formation of pyrite is a key process in several geochemical cycles, including maintenance of the oxygen content of the atmosphere (Wilkin \& Barnes 1996). It has also been proposed that the redox energy associated with pyrite evolution aided the formation of amide bonds, a significant reaction in studies of the origin of life (Wächtershäuser 1988). Despite these widespread implications, there remains significant controversy regarding the pathway and mechanism of pyrite formation and, in particular, the role of oxygen in these processes (Benning \& Barnes 1998, Benning et al. 2000, Wilkin \& Barnes 1996).

The importance of the hydrothermal Fe-S system warrants a thorough understanding of the solid-state reactions involved. We suspected that the absence of a consistent scheme of reactions is partially due to difficulties arising from changes in oxidation state. These changes likely take place in the crystalline, amorphous and aqueous phases present during the course of formation. Introduction of oxygen during sampling for ex situ determination of the phases present in the hydrothermal reaction vessels used for these studies could lead to irreproducible and conflicting results. Earlier studies have indicated, however, that the conversion of mackinawite to pyrite follows an oxidation process, although the oxidant remains in question.

The first step in the formation of iron sulfides under hydrothermal conditions is the nucleation of a reduced short-range-ordered iron monosulfide that is generally believed to be a precursor to mackinawite (Davison 1991, Parise et al. 1994, Rickard 1989, 1995, Schoonen \& Barnes 1991). Subsequently, mackinawite itself serves as a precursor to the stable phase, pyrite. Three primary pathways for this transformation have been proposed:

(1) Progressive sulfidation and conversion of iron monosulfides to pyrite (Berner 1970),

$$
\mathrm{FeS}+\mathrm{S}^{\circ} \rightarrow \mathrm{FeS}_{2}
$$

where FeS represents an iron monosulfide such as disordered mackinawite, mackinawite or greigite, and $S^{\circ}$ represents a source of sulfur (elemental, polysulfide, etc.).

(2) Transformation of iron monosulfide to pyrite occurs via the $\mathrm{H}_{2} \mathrm{~S}$ route (Drobner et al. 1990, Rickard 1997, Taylor et al. 1979), in which $\mathrm{H}_{2} \mathrm{~S}$ is the oxidant:

$$
\mathrm{FeS}+\mathrm{H}_{2} \mathrm{~S} \rightarrow \mathrm{FeS}_{2}+\mathrm{H}_{2}(\mathrm{~g})
$$

(3) Replacement reactions in terms of Fe loss:

$$
2 \mathrm{FeS}+2 \mathrm{H}^{+} \rightarrow \mathrm{FeS}_{2}+\mathrm{Fe}^{2+}+\mathrm{H}_{2}(\mathrm{~g})
$$

Such a reaction was investigated most recently by Wilkin \& Barnes (1996).

In a recent study, Lennie et al. (1997) examined the solid-state transformation of mackinawite to greigite. These experiments in particular showed the utility of in situ XRD by determining the crystal-chemical mechanism of transformation. Whereas the sample cell and beamline set-up for this study were appropriate for the investigation of a solid-state phase transition, full examination of the $\mathrm{Fe}-\mathrm{S}$ reaction sequence under controlled hydrothermal conditions was not possible. In the experiments reviewed here, we have investigated this conversion process both aerobically and anaerobically via time-resolved in situ $\mathrm{X}$-ray diffraction using sample cells that allow control of reaction conditions (Figs. 2, 3 ). Given the variety of observations in the literature, the ability to directly monitor the course of this transformation without compromising the reaction conditions (i.e., no quenching of the reaction was necessary to obtain diffraction data) was deemed important.

Starting materials and monochromatic XRD experiments: The steps for preparing and handling samples prior to in situ collection of X-ray data have been described in detail elsewhere (Benning et al. 2000). Furthermore, the energy-dispersion in situ XRD component of this study that uses the reaction cell shown in Figure 3 was described by Cahill et al. (2000).

In situ XRD experiments were done at beamline $\mathrm{X} 7 \mathrm{~B}$ of the NSLS, using monochromatic radiation and the capillary reaction cell. Details of the set-up of this beamline were reported previously (Gualtieri et al. 1996). Some specific parameters for this study are as follows: incident white radiation was monochromated via channel-cut $\mathrm{Si}(111)$ monochromators to the desired wavelength as determined from a unit-cell refinement of $\mathrm{LaB}_{6}$ (NIST SRM660a). The size of the incident beam was controlled via two upstream slits to be $1.0 \times$ $0.5 \mathrm{~mm}$. The sample cell (Fig. 2) was attached to a horizontally mounted Huber four-circle goniometer, and diffracted X-rays were collected on a TIP system (Norby 1996). Using this configuration, two types of experiments were done: anoxic and controlled oxic. 
Results of synchrotron (NSLS) powder-diffraction of $\mathrm{FeS} \rightarrow \mathrm{FeS}_{2}$ transformation under anoxic conditions: For these experiments, the goal was to increase sample density in order to produce a satisfactory diffraction signal while maintaining control over the $\mathrm{O}_{2}$ level. Such criteria proved difficult in the configuration of the hydrothermal autoclave cell (Fig. 3), as described previously (Cahill et al. 2000). These runs heated an ex situ prepared anoxic $\mathrm{Fe}-\mathrm{S}$ slurry to $120^{\circ} \mathrm{C}$ over 30 minutes and held for $3.5 \mathrm{~h}$. During this time, diffraction peaks solely from mackinawite were observed (Fig. 5). Several experiments at different temperatures $\left(90\right.$ to $\left.150^{\circ} \mathrm{C}\right)$ yielded similar results: for anoxically prepared $\mathrm{Fe}-\mathrm{S}$ slurries, mackinawite is the only Fe-sulfide phase observed under these conditions.

Results of synchrotron (NSLS) powder-diffraction of $\mathrm{FeS} \rightarrow \mathrm{FeS}_{2}$ transformation under oxic conditions: In order to investigate the role of $\mathrm{O}_{2}$ in the hydrothermal $\mathrm{Fe}-\mathrm{S}$ system, the above experiment was repeated with an aerated starting material. Specifically, compressed air was bubbled through a second ex situ prepared $\mathrm{Fe}-\mathrm{S}$ slurry. After this treatment, the sample mixture was heated in situ to $150^{\circ} \mathrm{C}$ over 30 minutes and held for approximately $2 \mathrm{~h}$. As expected, this oxygenated experiment showed rapid disappearance of mackinawite followed by the appearance of greigite after approximately 30 minutes (Fig. 6). The onset of pyrite is observed at about 40 minutes, followed by the formation of magnetite at about 60 minutes. Goethite is present throughout almost the entire run. In Figure 6, the large increase in background scatter (as compared to Fig. 5) between $10^{\circ}$ and $35^{\circ} 2 \theta$ is due to a decrease in the sample density after treatment with compressed air. The slurry was disturbed in the process and, owing to time constraints, not allowed to settle completely prior to loading for the in situ experiment.

Discussion and remarks: The capillary reaction cell (Fig. 2) and sample preparation used at the NSLS allowed a higher density of solids in the path of the incident X-ray beam as compared to the hydrothermalbomb-type cell (Fig. 3) (Cahill et al. 2000), thus providing an adequate $\mathrm{X}$-ray-diffraction signal. The re-

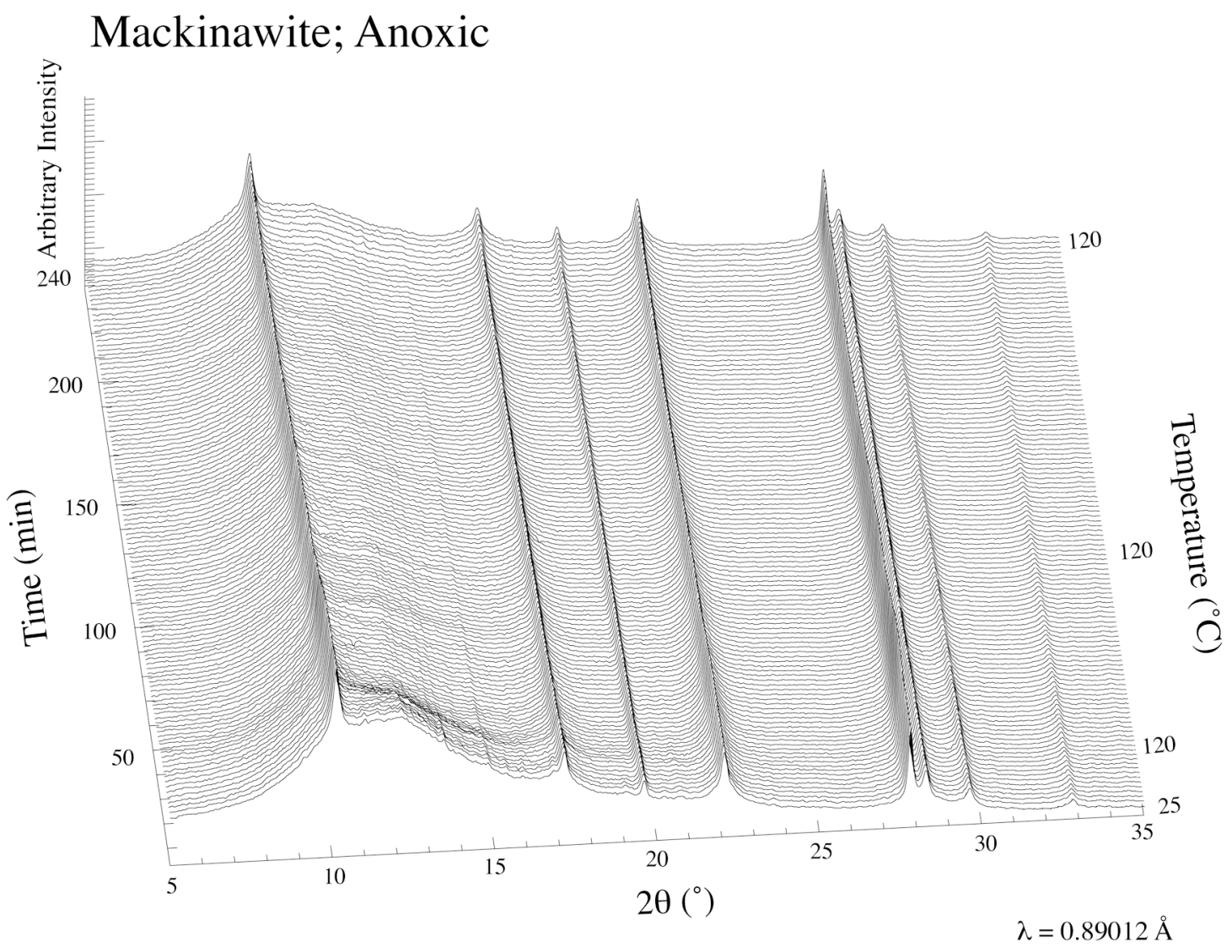

FIG. 5. Time-resolved powder-diffraction patterns of an ex situ prepared anoxic slurry heated to $120^{\circ} \mathrm{C}$ as obtained in the capillary reaction cell. FeS (mackinawite) is the only observed sulfide phase after $3.5 \mathrm{~h}$ under reduced anoxic conditions. 


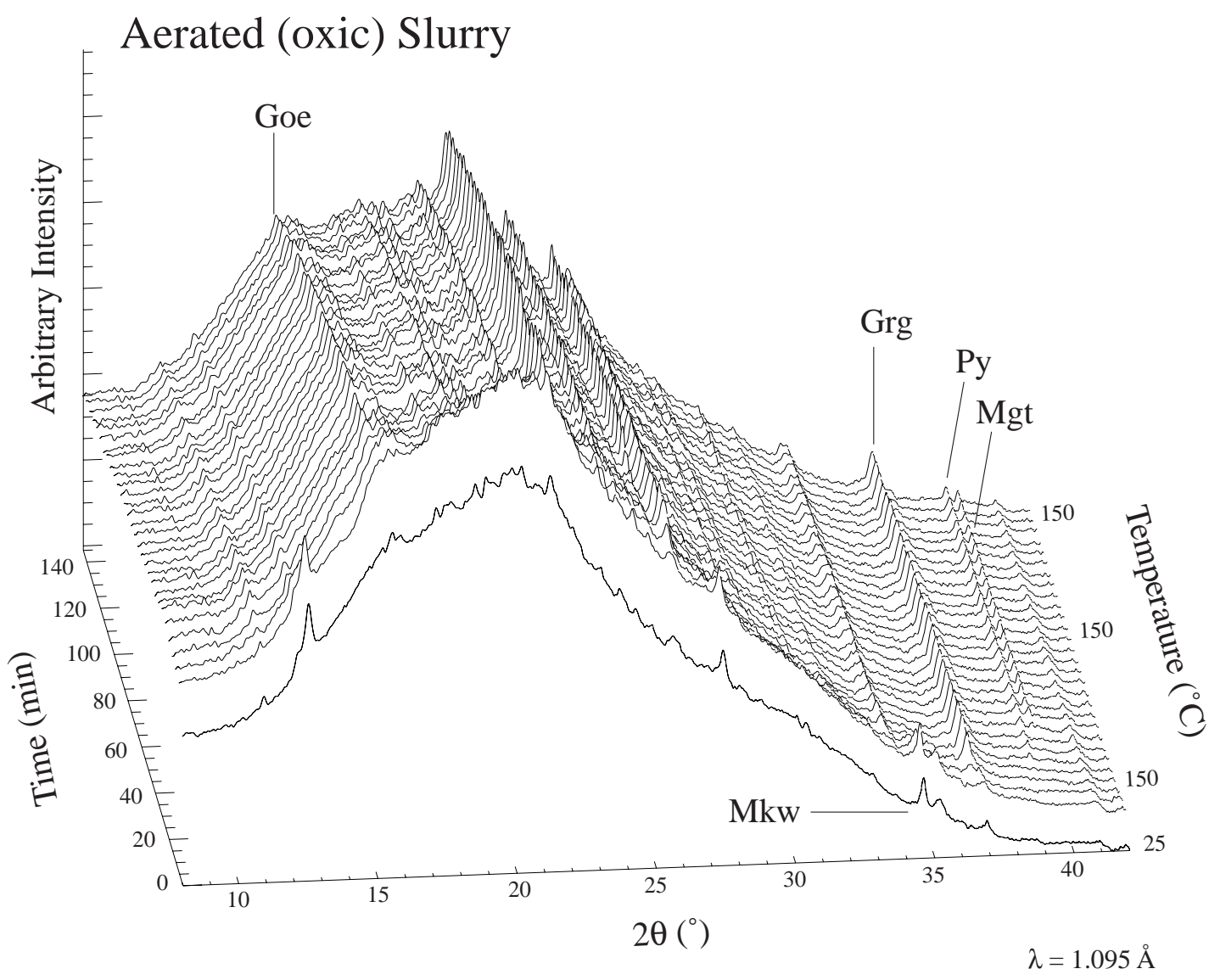

FIG. 6. Time-resolved powder-diffraction patterns of an ex situ prepared aerated slurry heated to $150^{\circ} \mathrm{C}$. Note the rapid disappearance of mackinawite as it is replaced by greigite, goethite, pyrite and magnetite under these oxic conditions.

sults of the anoxic experiments with this set-up show the persistence of mackinawite to at least $150^{\circ} \mathrm{C}$, suggesting that the monosulfide-conversion mechanism shown in equation [2] does not occur. Furthermore, no other $\mathrm{Fe}-\mathrm{S}$ phases were observed after $3.5 \mathrm{~h}$ of reaction, in contrast with previous observations. During oxic experiments, however, the formation of greigite, pyrite, goethite and magnetite was observed, indicating that the mackinawite $\rightarrow$ greigite $\rightarrow$ pyrite transformation sequence occurs only where conditions are not anaerobic. A more thorough discussion of reaction mechanisms can be found in Cahill et al. (2000).

In summary, the experimental techniques used in this study illustrate the applicability to a number of systems. The ability to maintain anoxia under hydrothermal conditions without interruption for sampling shows the potential for thorough studies over a range of sample environments. As these were the first in situ XRD experiments of the hydrothermal $\mathrm{Fe}-\mathrm{S}$ system, further op- timization of experimental parameters will allow acquisition of data suitable for kinetic studies and Rietveld analysis. In their current configurations, neither of the above cell types (capillary or autoclave) is particularly suited to study the early stages of FeS nucleation reactions. Rather, other synchrotron-based techniques such as simultaneous SAXS-WAXS (small- and wide-angle X-ray scattering, respectively) experiments may make a contribution to our understanding of these reactions (de Moor et al. 1997, Shaw et al. 2000c).

\section{Characterization of ion exchange in zeolite LSX}

The mechanisms of ion exchange in microporous and layered solids, such as zeolites and clays, have important implications in areas as diverse as soil fertility and environmental remediation. Detailed characterization of the process whereby site-specific exchange occurs, along with the effects of different types of cations 
on the uptake and release of ions, is best realized using a probe that is both time- and structure-sensitive (Lee et al. 1998b). To discern the mechanism, it is necessary not only to observe the course of the reaction and its outcome, but also to collect dynamic X-ray-diffraction data of sufficient quality to allow structure refinement using the Rietveld technique.

An illustration of this approach is provided by investigating the exchange systems of $\mathrm{K} \leftrightarrow \mathrm{Na}, \mathrm{Sr} \rightarrow \mathrm{Na}$ and $\mathrm{Sr} \rightarrow \mathrm{K}$ in low-silica X-type zeolite (LSX) (Lee et al. 1998b). LSX is one of the synthetic counterparts of faujasitic zeolites and has a Si:Al ratio of 1 (Kuhl 1987), and hence the maximum possible number of exchangeable cations. Faujasite consists of a negatively charged aluminosilicate framework with two interconnecting three-dimensional networks of cavities (Breck 1984) containing interstitial cations (Fig. 7). The larger cavities, called supercages or 26-hedron cages, have a free diameter of about $13 \AA$, and are linked by sharing rings of twelve tetrahedra (12-ring windows) that have a free diameter of about $8 \AA$. The smaller cavities in sodalite, called beta cages or truncated octahedral cages, have a free diameter of about $7 \AA$, and are linked in a diamondtype lattice through rings of six tetrahedra (6-ring windows, S6R) to form the hexagonal double six-ring prisms (D6R) between the sodalite cages (Fig. 7). The S6R of the sodalite cage has a free diameter of about $2.5 \AA$, and is therefore capable of allowing certain exchangeable cations or molecules into the sodalite cage and the D6R (Fig. 7). Cations are located at preferred interstitial sites, which, in the case of X-type zeolites, are the so-called type I, I', II and III' sites (Fig. 7).

To investigate the ion-exchange mechanisms in LSX, a combination of time-resolved synchrotron X-ray powder-diffraction data collected with a TIP and Rietveld structure refinement was used. $\mathrm{K} \rightarrow \mathrm{Na}$ exchange proceeds through a two-phase region in agreement with the result of the ex situ study (Lee et al. 1998a, b). $\mathrm{Sr} \rightarrow \mathrm{Na}$ exchange proceeds via a narrow miscibility gap consistent with the model of Olson \& Sherry (1968), whereas a single phase is maintained throughout the course of $\mathrm{Sr} \rightarrow \mathrm{K}$ exchange. Changes in occupancy of each site suggest that ion exchange in LSX is cation-

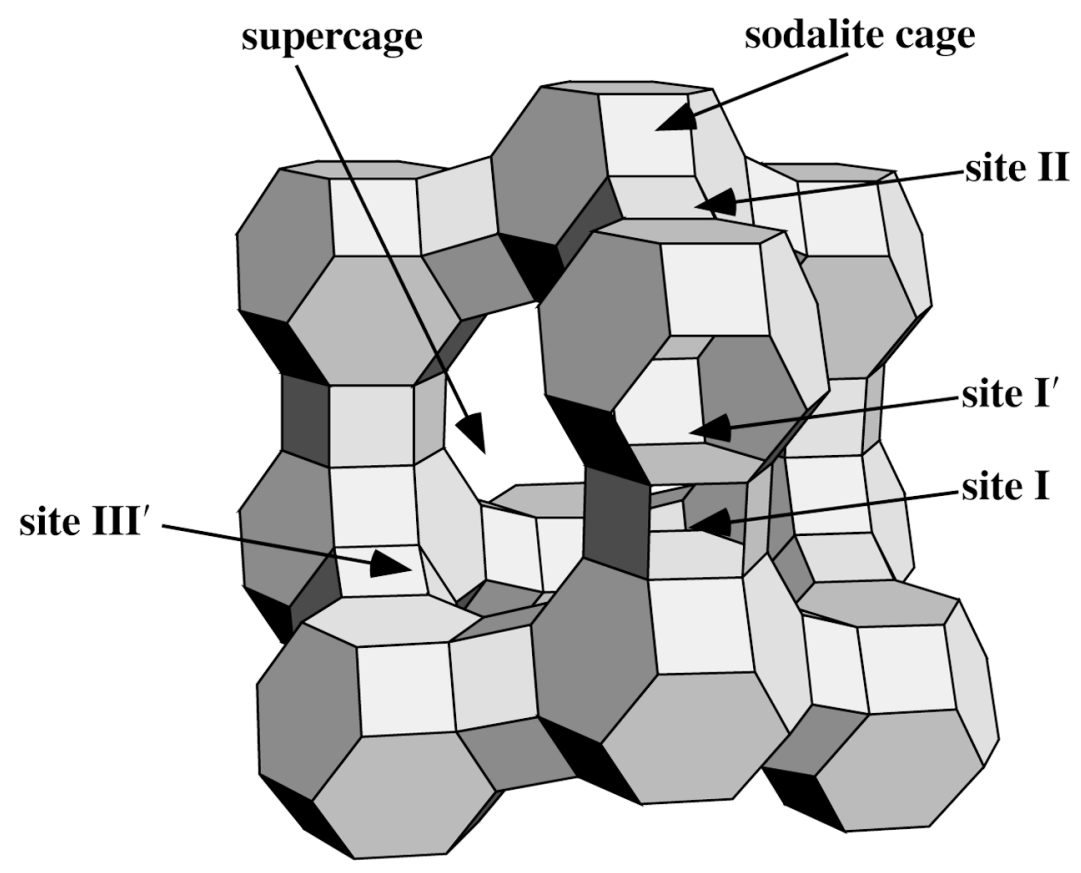

FIG. 7. Polyhedral representation of the faujasite framework. Nodes represent the centers of $(\mathrm{Si}, \mathrm{Al}) \mathrm{O}_{4}$ tetrahedra, and straight-line sections represent the $T-\mathrm{O}-T$ linkage $(T=$ $\mathrm{Si}, \mathrm{Al}$ ). Cation sites are located in the middle of the double six-membered rings (site I), close to the six-membered rings both in the sodalite cage (site $I^{\prime}$ ) and in the supercage (site II), and close to the four-membered rings (site III'). Designation of each interstitial site in this study follows the nomenclature of Olson \& Sherry (1968). 
dependent and site-specific, a result that would have been difficult to obtain with static measurements.

Starting materials and monochromatic XRD experiments: Synthesis of LSX was described previously by Kuhl (1987) and Lee et al. (1998b). Pure Na- and Kforms of LSX were prepared and used as starting materials for the in situ ion-exchange experiments (Lee et al. 1998b).

Time-resolved powder-diffraction studies using a TIP system were performed at beamline X7B of the NSLS. Each powdered sample of $\sim 0.003 \mathrm{~g}$ was loaded into a $0.7-\mathrm{mm}$ quartz capillary that was plugged with glass fibers at both ends (Fig. 4). This capillary was mounted on the SECReTS cell (Fig. 4), and a 0.01 $\mathrm{M}$ of each exchange solution ( $\left.\mathrm{KCl}, \mathrm{NaCl}, \mathrm{SrCl}_{2} \bullet 6 \mathrm{H}_{2} \mathrm{O}\right)$ was passed over the sample using an $\mathrm{N}_{2}$ overpressure of 2030 psi at room temperature. For $\mathrm{K} \rightarrow \mathrm{Na}$ exchange, the TIP detector recorded the diffraction pattern over $6 \mathrm{~h}$ $(\lambda=0.9949 \AA$ ) behind a slit of width $3 \mathrm{~mm}$ with a step size of $0.2 \mathrm{~mm}$ and a step-counting time of $24 \mathrm{~s}$. A monochromatic beam of $\lambda=0.9511 \AA$ was used for $\mathrm{Na}$ $\rightarrow \mathrm{K}, \mathrm{Sr} \rightarrow \mathrm{Na}$ and $\mathrm{Sr} \rightarrow \mathrm{K}$ exchange, and step-counting times of 20,12, and $18 \mathrm{~s}$ were used, respectively. Figures 8-11 show the time-resolved synchrotron X-ray powder-diffraction profiles from each in situ ion-exchange experiment.

A similar setup with a CCD detector was used at beamline X7A of the NSLS to describe the $\mathrm{K} \rightarrow \mathrm{Na}$ exchange system. The detector was set at $2 \theta=23^{\circ}$ and sample-to-detector distance of $30.9 \mathrm{~cm}$, covering a $2 \theta$

\section{$\mathrm{K} \rightarrow \mathrm{Na}$ exchange in LSX}

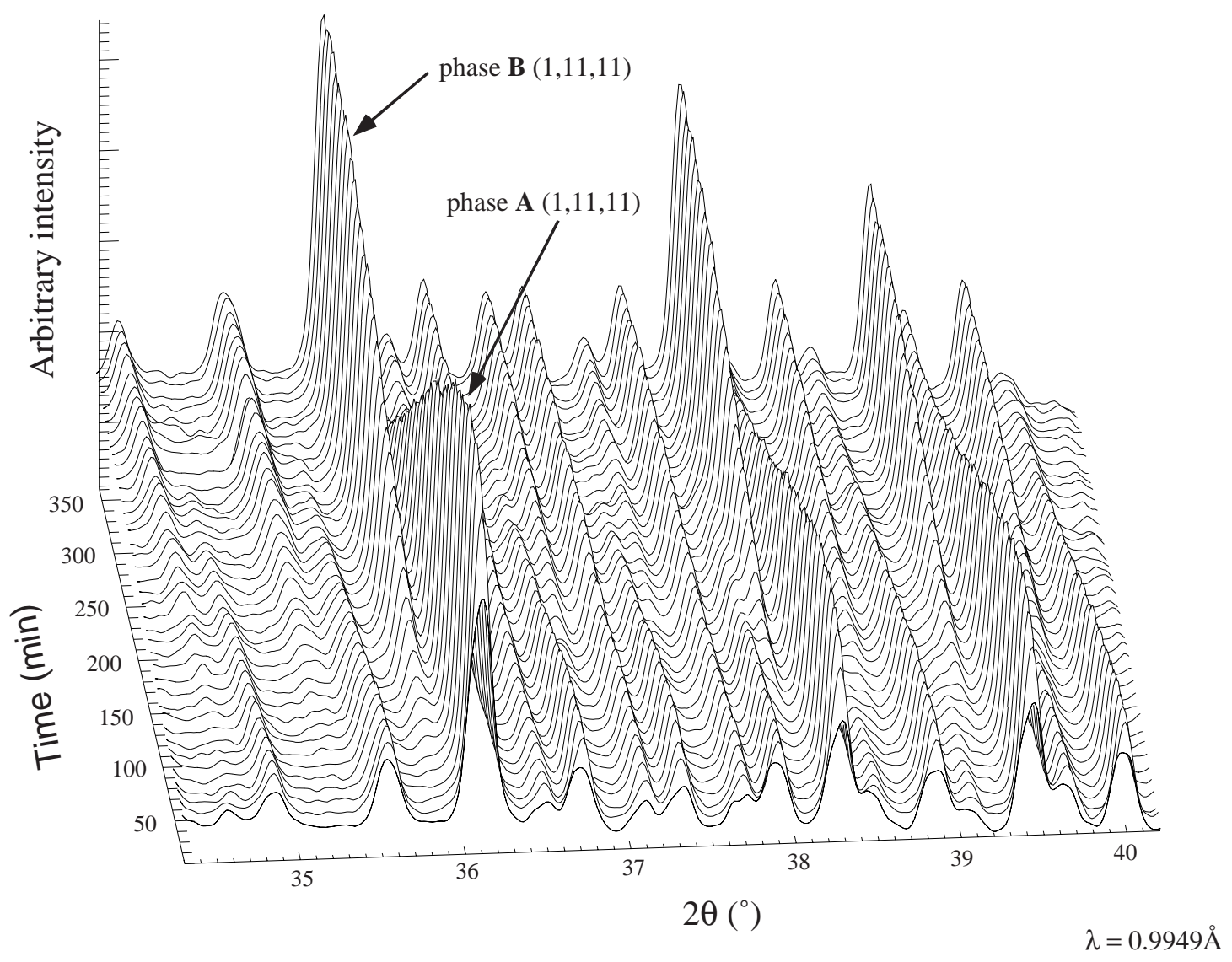

FIG. 8. Plot of the synchrotron X-ray powder-diffraction profiles as a function of time during the $6 \mathrm{~h}$ of $\mathrm{K}$-exchange into NaLSX. The patterns are obtained by integrating the imaging plate vertically with an integration width of $3 \mathrm{~mm}$, about the size of the slit. 


\section{$\mathrm{Na} \rightarrow \mathrm{K}$ exchange in LSX}

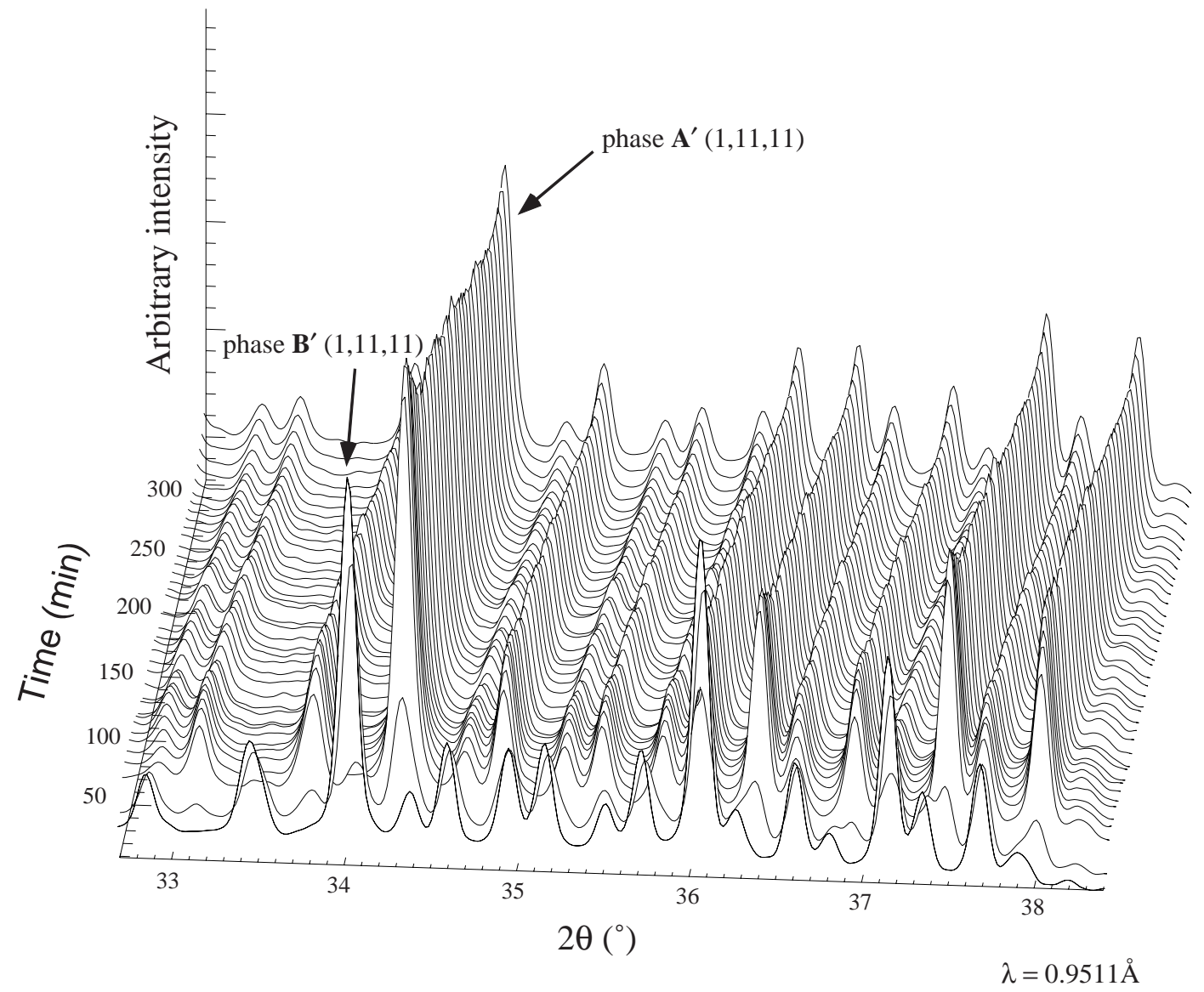

FIG. 9. Plot of the synchrotron X-ray powder-diffraction profiles during the $5 \mathrm{~h}$ of Na-exchange into K-LSX.

range from $17.7^{\circ}$ to $28.2^{\circ}(\lambda=0.7000 \AA)$. Diffraction patterns were recorded every $60 \mathrm{~s}$ on a SMART $1 \mathrm{~K}$ CCD area detector without the slits (Fig. 4).

Rietveld refinement was done using the GSAS suite of programs (Larson \& Von Dreele 1986) and sets of data integrated to represent 6-8 min portions during each in situ scan (Norby 1997b). The structural parameters from the ex situ study (Lee et al. 1998b) were used to construct and constrain the starting models. As changes in cation distribution are important to understand the ion-exchange process, only positions and occupancies of cations and $\mathrm{H}_{2} \mathrm{O}$ groups were refined. The site III' was modeled using the scattering factor for $\mathrm{O}$ owing to the possible disordering of the interstitial atoms at this site (Mortier \& Bosmans 1971) (Fig. 7). Figure 12 shows the changes in cation distributions inferred using the Rietveld refinements and the time- resolved data, along with the plots of the cell parameters as a function of time.

Results of the synchrotron (NSLS) in situ powderdiffraction of $K \rightarrow \mathrm{Na}$ exchange in LSX: This system was discussed in detail in the previous ex situ and in situ reports (Lee 1998a, b). Only one set of peaks was observed during the first 30 minutes (Fig. 8). Two sets of peaks, which could be indexed as two separate facecentered cubic phases, were present after this stage. The second set of peaks was shifted to a lower- $2 \theta$ value relative to the peaks from the original phase, indicating a larger unit-cell. These two phases are designated as $\mathbf{A}$ and $\mathbf{B}$ (Fig. 8) for the discussion below.

Kinetic information and which initial patterns to use for Rietveld refinement were obtained using ITTFA (Liang et al. 1996). Four different "components" (Fig. 13a) were identified from the time-resolved data 
(a)

\section{$\mathrm{Sr} \rightarrow \mathrm{Na}$ exchange in LSX}

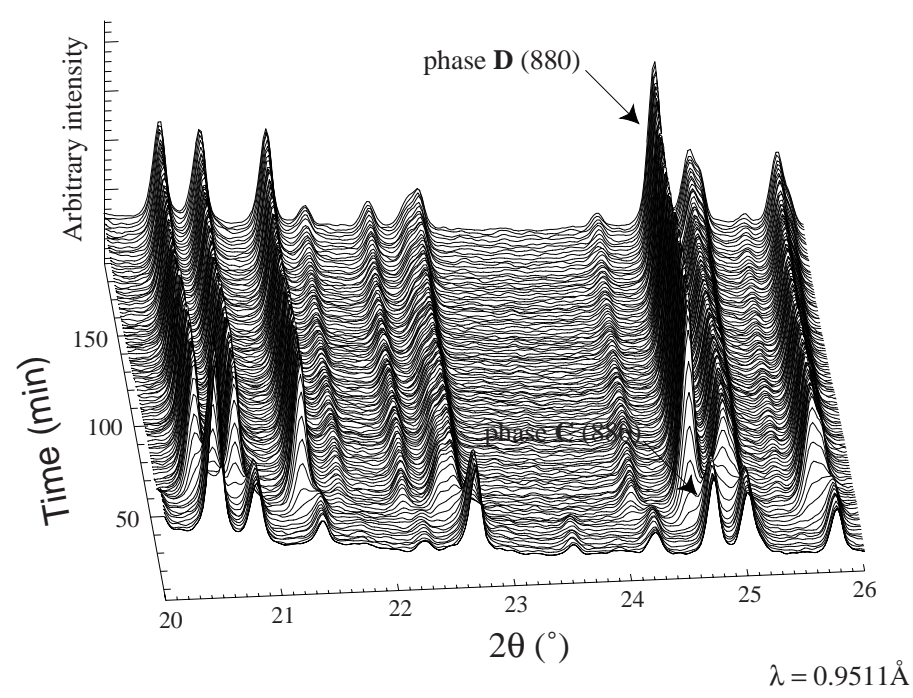

(b)

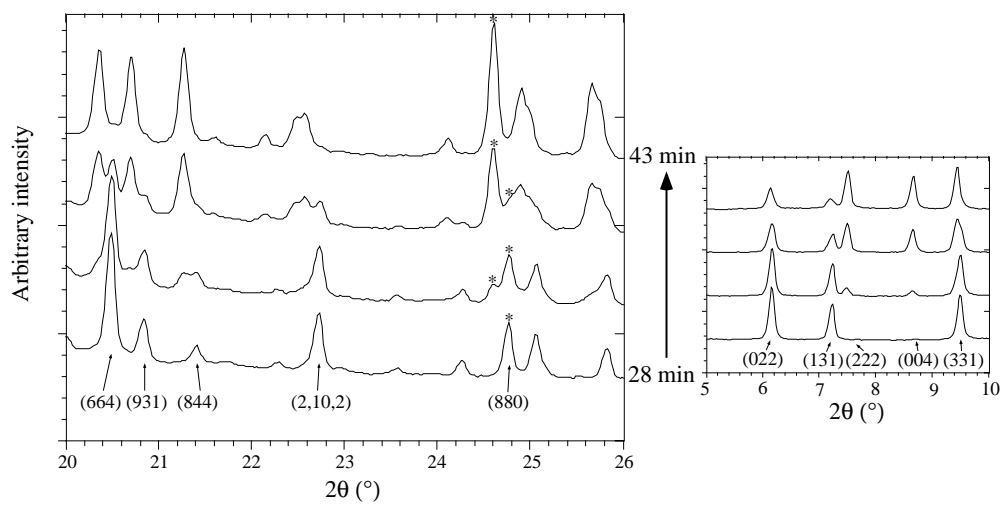

FIG. 10. (a) Plot of the synchrotron X-ray powder-diffraction profiles during the $3 \mathrm{~h}$ of $\mathrm{Sr}$ exchange into Na-LSX. (b) Details of Sr-exchange into Na-LSX during its initial period. A reflection with an asterisk marks the formation of phase $\mathbf{D}$ and the disappearance of phase $\mathbf{C}$. Changes in the low-angle region (right) also are shown for comparison.

(Fig. 8). Component 1 is attributed to the errors associated with the geometry of the IP. Components 2 and 4 represent the disappearance of phase $\mathbf{A}$ and the growth of phase $\mathbf{B}$, respectively, whereas component 3 represents the two-phase region where phases $\mathbf{A}$ and $\mathbf{B}$ are present. By combining components 2,3 , and 4 , normalized fractions were plotted against reaction time (Fig. 13b). Fits to the Avrami equation (Avrami 1941), $[a=$ $\left.1-\exp (-k t)^{n}\right]$, where $a$ is a normalized fraction of each component phase, allowed us to derive a rate constant (k) of $4 \times 10^{-6}$ and $n=2.3$. This result suggests a diffusion-controlled process with a decreasing rate of nucleation (Clark et al. 1994, Hulbert 1969, Norby 1997a).

The unit cell of phase A decreases initially, whereas that of the larger-volume phase $\mathbf{B}$ shows a continuous increase from its formation (Fig. 12a). These proportions become constant at the end of the $6 \mathrm{~h}$ in situ scan. The initial and final cell dimensions inferred from the in situ experiment are consistently larger than those from the ex situ study: 25.134(1)-25.281(1) ̊ compared to 
(a)

$$
\mathrm{Sr} \rightarrow \mathrm{K} \text { exchange in LSX }
$$

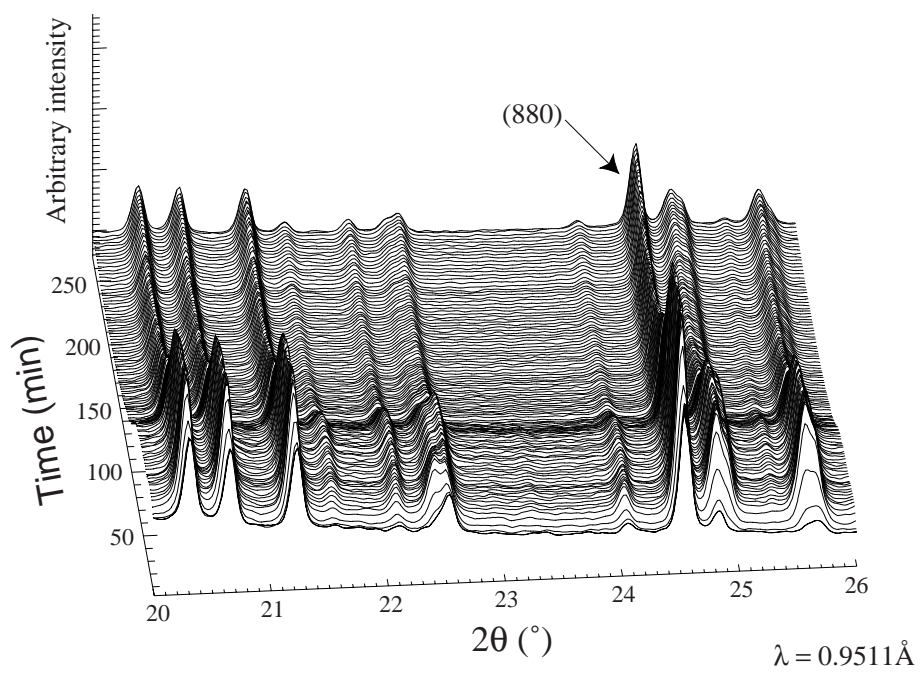

(b)

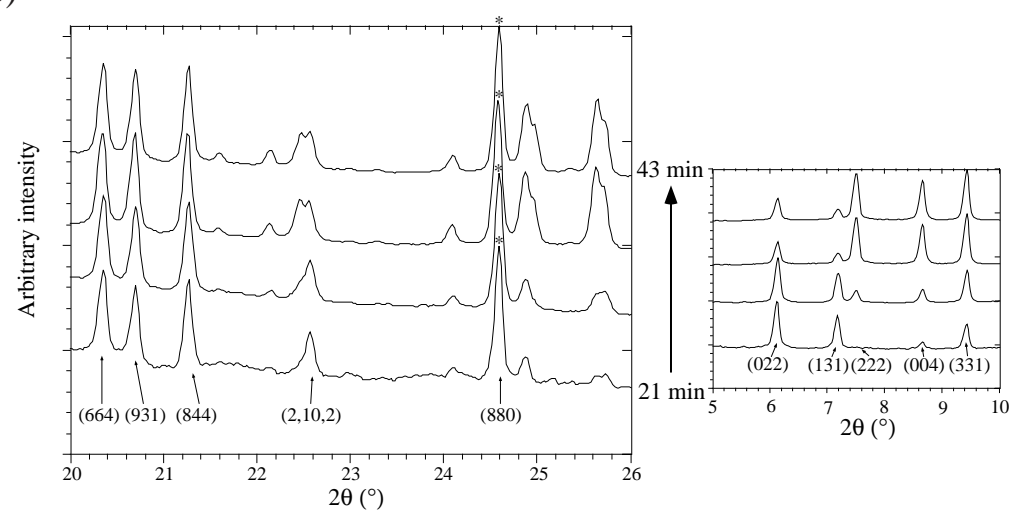

FIG. 11. (a) Plot of the synchrotron X-ray powder-diffraction profiles during the $4.5 \mathrm{~h}$ of Sr-exchange into K-LSX. (b) Details of Sr-exchange into K-LSX during its initial period. A reflection with an asterisk indicates that a single phase is preserved. Changes in the low-angle region (right) also are shown for comparison.

25.0491(3)-25.2486(3) A, respectively (Fig. 12a). The difference is attributed to the difference in hydration in each experimental condition (Lee et al. 1998a, b).

Changes in occupancies of sites I, I' and II by K indicate a time-dependent and site-specific ion-exchange process (Fig. 12b). As in the ex situ study (Lee et al. 1998b), $\mathrm{K}$ first replaces $\mathrm{Na}$ at site II in phase $\mathbf{A}$. The occupancy of site II by $\mathrm{K}$ increases until $\mathrm{Na}$ at site I' begins to exchange, at which stage phase $\mathbf{B}$ appears. In phase $\mathbf{B}$, the occupancies of sites I and I' by $\mathrm{K}$ trend in opposite direc- tions, suggesting diffusion of $\mathrm{K}$ from site I' to site I (Fig. 12b). There is a continuous increase in the occupancy of site II by $\mathrm{K}$ from the formation of phase $\mathbf{B}$.

To investigate the initial stages of this reaction, a CCD detector was set for higher time-resolution (60-s exposures via the quasi-real time scan). A model for the initial stage of K-exchange in Na-LSX is proposed by comparing a calculated powder-diffraction pattern with a CCD-detector observation (Fig. 14). Combining the results of the simulation and Rietveld refinements, the 
(a)

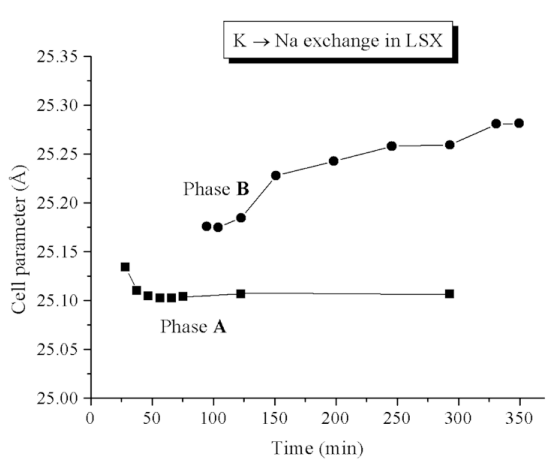

(c)

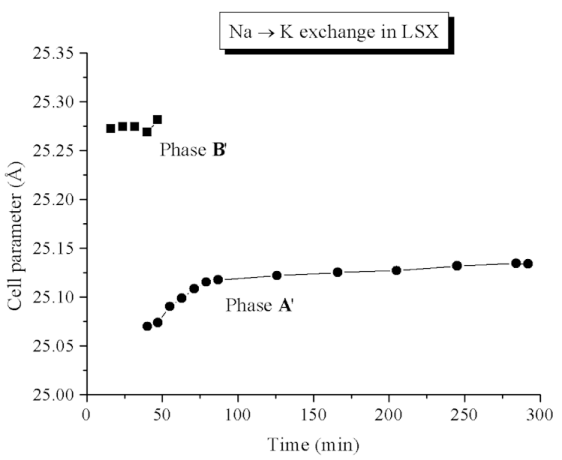

(e)

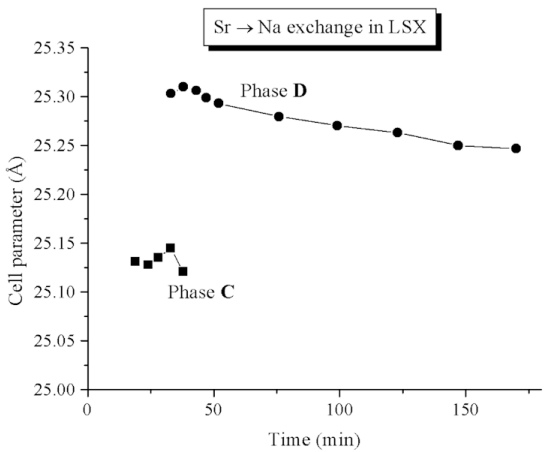

(g)

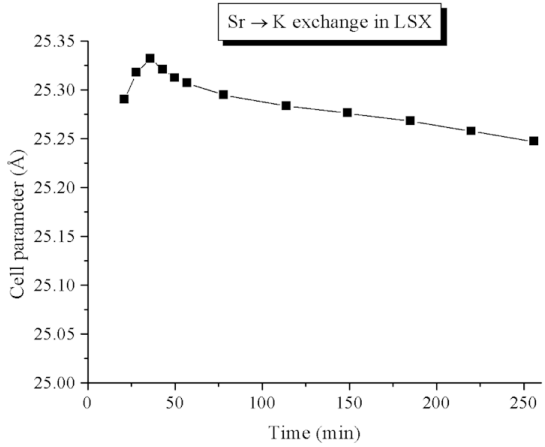

(b)

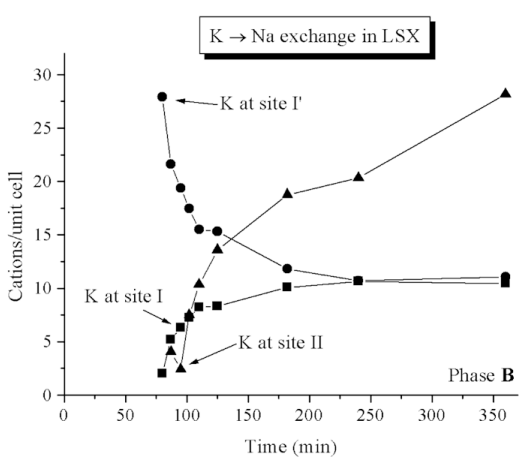

(d)

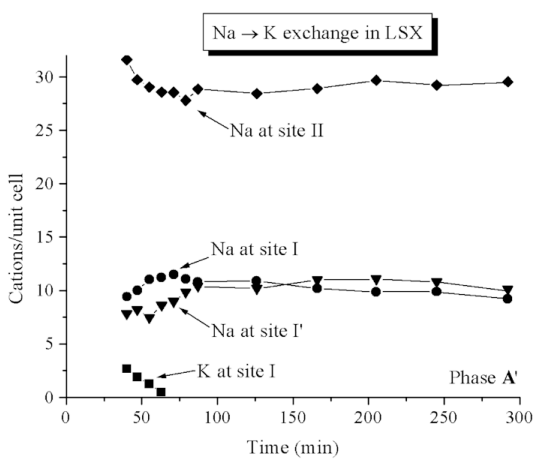

(f)

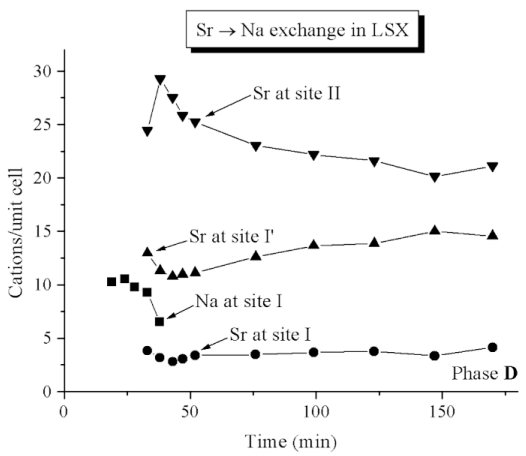

(h)

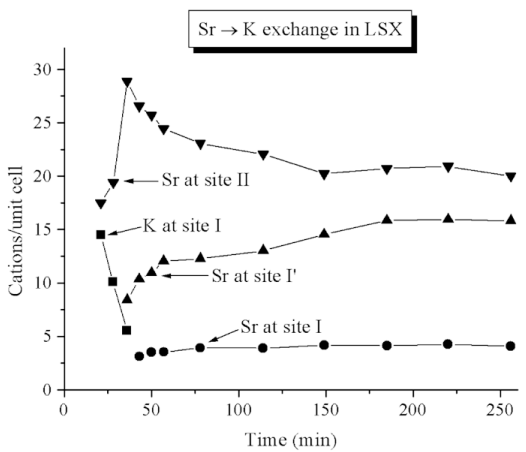

FIG. 12. Variations of cell parameters and cation distributions as a function of time. 
(a)

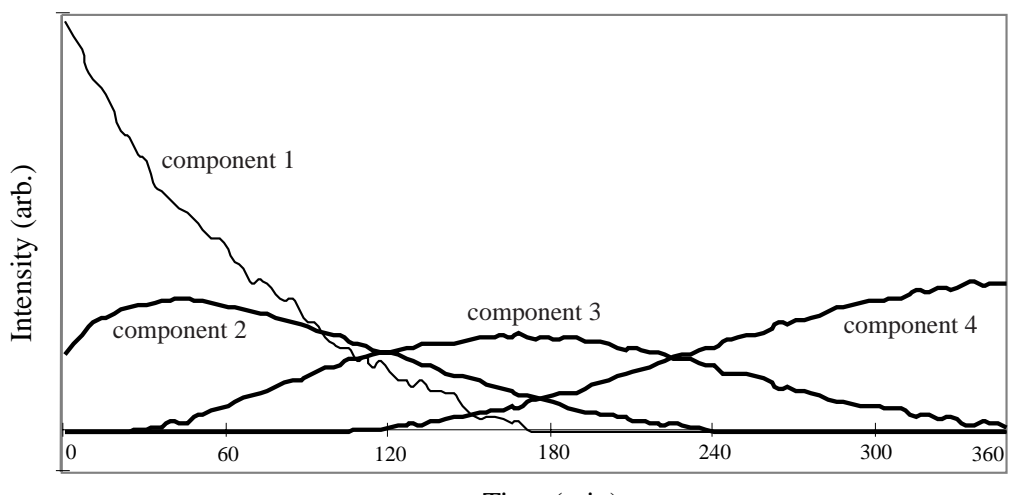

Time (min)

(b)

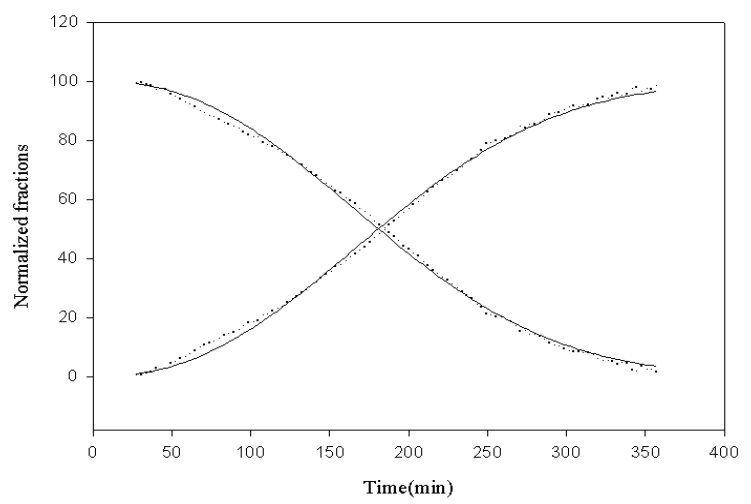

FIG. 13. (a) ITTFA results showing the four "components" of the K-exchange into NaLSX. Components 2, 3 and 4 are emphasized with bold lines. (b) Normalized fractions of the combined components 2, 3 and 4 and fits to the Avrami (1941) equation.

following pathway for K-exchange in Na-LSX is drawn. Potassium first replaces $\mathrm{Na}$ at sites II and III' in the supercage in the early stage of the exchange (Fig. 14). This transient step is followed by diffusion of $\mathrm{K}$ to the sodalite cage, where $\mathrm{Na}$ at site I' is then exchanged. With those sites loaded with $\mathrm{K}$, the openings of the S6R increase, and further $\mathrm{K}$ exchange causes a unit-cell expansion by positioning $\mathrm{K}$ at site $\mathrm{I}$, the D6R site (Figs. $12 \mathrm{a}, \mathrm{b})$.

Results of the synchrotron (NSLS) in situ powderdiffraction of $\mathrm{Na} \rightarrow \mathrm{K}$ exchange in LSX: The structural response of Na-LSX on K-uptake involved a cell expansion caused by site-specific ion-exchange. To extend this idea and test the reversibility of the system, Na-exchange into K-LSX was done. One set of peaks was observed during the first 30 minutes of the $5 \mathrm{~h}$ in situ scan (Fig. 9). Two sets of peaks, indexed as two sepa- rate face-centered cubic phases, coexisted for 10 minutes after this initial stage. The peaks of the new phase were shifted to higher- $2 \theta$ values relative to those of the original phase and hence indicated a smaller unit-cell. Only the new phase persisted throughout the rest of the in situ scan. These two phases are designated as $\mathbf{B}$ ' and $\mathbf{A}^{\prime}$ (Fig. 9) for the discussion below.

The cell dimensions of phases $\mathbf{B}^{\prime}$ and $\mathbf{A}^{\prime}$ (Fig. 12c) are related to those of phases $\mathbf{A}$ and $\mathbf{B}$ (Fig. 12a). Phase B' does not show any significant change in cell dimension from its initial value of 25.272(1) $\AA$. This value is close to the final cell constant of phase B [25.281(1) $\AA$ ], which, in turn, is indicative that the $\mathrm{K} \rightarrow \mathrm{Na}$ exchange was complete. Phase $\mathbf{A}^{\prime}$ exhibits an increase in cell parameter from its initial value of 25.070(1) $\AA$ and slowly approaches $25.134(1) \AA$. This value is equal to the ini- 


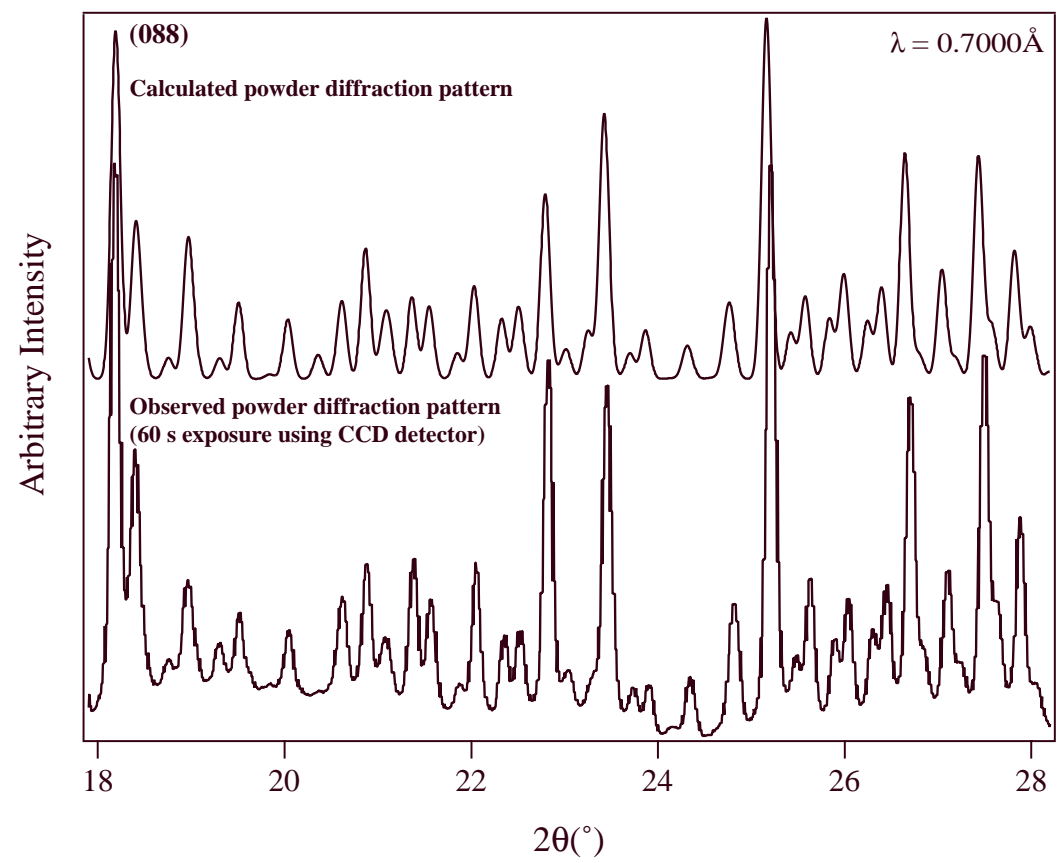

FIG. 14. Calculated and observed (CCD) powder-diffraction patterns, showing the initial transient model in the $\mathrm{K} \rightarrow \mathrm{Na}$ exchange where $\mathrm{Na}^{+}$ions of the wall sites in the supercage (sites II and III') are first replaced by $\mathrm{K}^{+}$ions.

tial cell constant of phase $\mathbf{A}$ (Fig. 12a) and suggests that the $\mathrm{Na} \rightarrow \mathrm{K}$ exchange was complete.

Changes in the cation distributions in phases $\mathbf{B}^{\prime}$ and $\mathbf{A}^{\prime}$ suggest that the cell contraction is caused by $\mathrm{Na}$ replacing $\mathrm{K}$ in the D6R (Fig. 12d). This is analogous to the mechanism observed in the $\mathrm{K} \rightarrow \mathrm{Na}$ exchange (Fig. 12b) and shows that the K-Na-LSX system is reversible. Smaller $\mathrm{Na}(\mathrm{r} \approx 1.00 \AA)$ can enter site I more efficiently than $\mathrm{K}(\mathrm{r} \approx 1.38 \AA)$, which causes the cell to contract abruptly. An isothermal study of this system is currently underway.

Results of the synchrotron (NSLS) in situ powderdiffraction of $\mathrm{Sr} \rightarrow \mathrm{Na}$ exchange in LSX: Ion-exchange behavior that involves a two-phase system in X-type zeolites was first reported by Olson \& Sherry (1968) in the context of an investigation of $\mathrm{Sr} \rightarrow \mathrm{Na}$ solid solution in Linde X. By studying bulk samples at different Sr loading levels, they discovered a miscibility gap and explained the unusual behavior of the isotherm observed by Sherry (1968). Using in situ synchrotron X-ray powder-diffraction, we have followed this system in LSX to discern the details of the exchange mechanism.

One set of peaks was observed during the first 30 minutes of the $3 \mathrm{~h}$ in situ scan (Fig. 10). The second set of peaks began to grow as shoulders on the low-angle sides of the peaks from the original phase. These separate faujasite-type phases coexisted for approximately
10 minutes. This formation of a larger-volume phase is consistent with the results of Olson \& Sherry (1968). Only the second set of peaks remained throughout the rest of the in situ scan. These two phases are designated as $\mathbf{C}$ and $\mathbf{D}$ (Fig. 10) in the following discussion.

Changes in the cell parameters of phases $\mathbf{C}$ and $\mathbf{D}$ are shown in Figure 12e. The unit cell of phase $\mathbf{C}$ increases slightly until phase $\mathbf{D}$ forms. In phase $\mathbf{D}$, the unit cell continues to decrease from 25.303(1) to 25.247(1) $\AA$. The initial unit-cell parameter of phase C, 25.131(1) $\AA$, which represents that of pure Na-LSX, is close to the final value of phase $\mathbf{A}^{\prime}$ (Fig. 12c).

The structure models determined for phases $\mathbf{C}$ and D differ in the occupancy of site I. Phase $\mathbf{C}$ has $\mathrm{Na}$ at sites I, I' and II, whereas phase $\mathbf{D}$ has $\mathrm{Sr}$ at site I (Fig. 12f). The occupancy of site I by $\mathrm{Sr}$ is responsible for the larger unit-cell volume. This is analogous to the mechanism observed in the $\mathrm{K} \leftrightarrow \mathrm{Na}$ system. No significant changes in occupancy were detected after the first hour of the in situ scan.

Results of the synchrotron (NSLS) in situ powderdiffraction of $\mathrm{Sr} \rightarrow \mathrm{K}$ exchange in LSX: The presence of a miscibility gap in the $\mathrm{K}-\mathrm{Na}$ and $\mathrm{Sr}-\mathrm{Na}$ solid solution in LSX prompted us to investigate the Sr-K-LSX system. Only one set of peaks was observed during the $4.5 \mathrm{~h}$ of the in situ scan (Fig. 11). The cell parameter continuously decreased from $25.290(1)$ to $25.247(1) \AA$ 
(Fig. 12g). The initial cell parameter, which represents that of pure K-LSX, is similar to the final unit-cell parameter of phase $\mathbf{B}$ (Fig. 12a), and the final unit-cell parameter is equal to that of phase $\mathbf{D}$ (Fig. 12e).

Changes in the cation distribution are shown in Figure $12 \mathrm{~h}$. Strontium first replaces K at site II; this seems to cause $\mathrm{K}$ at site I to diffuse out of the D6R (Fig. 8). The Sr-exchange proceeds to site I' and finally occurs at site I. After $\mathrm{K}$ is completely removed from site I, the occupancy of site II by Sr starts to decrease, indicating diffusion of Sr from site II to sites I' and I (Fig. 12h). The structural models at the end of $\mathrm{Sr} \rightarrow \mathrm{Na}$ and $\mathrm{Sr} \rightarrow$ K exchange are similar to each other (Figs. 12f, h), confirming the completion of Sr-exchange in both experiments.

Discussion and remarks: Time-resolved synchrotron $\mathrm{X}$-ray powder-diffraction was used to investigate $\mathrm{K}-\mathrm{Na}$, $\mathrm{Sr}-\mathrm{Na}$ and $\mathrm{Sr}-\mathrm{K}$ solid solution in LSX. The results from the previous NMR and ex situ study formed the starting models and constraints. Potassium or strontium at site I in the D6R characterized the new expanded phase formed at the expense of Na-LSX. Careful examination of the zeolite-X structure indicates that expansion or contraction of the D6R potentially has the most impact on structural parameters. Strontium replaced $\mathrm{K}$ at sites II and I', and finally at site I, in K-LSX without any abrupt expansion or contraction of the unit-cell volume.

The extraction of kinetic information from ITTFA treatment of the time-resolved data, although preliminary, has shown the potential for this combination of techniques in in situ X-ray-diffraction experiments. The use of a CCD detector enabled us to observe the initial stage of the $\mathrm{K} \rightarrow \mathrm{Na}$ exchange, in which $\mathrm{Na}$ at the supercage wall sites, II and III', was first replaced by K. Information on the activation energy at each site can be derived from in situ experiments performed at different temperatures and will form a basis to tailor properties such as selective adsorption as a function of cation distribution.

\section{Conclusion and Future Prospects}

As the availability of synchrotron X-ray sources and awareness of their capabilities for diffraction studies have grown, so has subscription at the beamlines capable of these measurements. Compared to other measurements, the diffraction experiment can take longer to set up and can require more careful planning to decide which combination of energy, resolution and detection systems (Fig. 1) is best matched to the problem at hand. The pay-off is a more straightforward interpretation of results, largely attributed to a comparatively simple scattering theory. The next generation of beamlines is being designed with flexibility in mind, and efforts must be made to ensure the ability to work at the limits of what is possible, given the brighter more energetic beams available at these third-generation sources.

\section{ACKNOWLEDGEMENTS}

We are grateful to collaborators at Penn State (L. Benning and H. Barnes), the NSLS (D. Cox, P. Norby, P. Stephens and J.C. Hanson) and the APS (M. Rivers, S. Sutton and J. Pluth). This work is sponsored by the NSF. The NSLS beamlines are supported by the USDOE Chemistry and Materials programs. CARS beamlines owe much to the early and continuing vision of J.V. Smith and the generous support of the NSF, DOE and the KECK Foundation. CLC wishes to thank the Mineralogical Society of America for a Research Grant in Crystallography from the Edward H. Kraus Crystallographic Research Fund.

\section{REFERENCES}

Andersen, E.K., ANdersen, I.G.K., Norby, P. \& Hanson, J.C. (1998): Kinetics of oxidation of fuel cell cathode materials lanthanum strontium manganates(III)(IV) at actual working conditions: in-situ powder diffraction studies. J. Solid State Chem. 141, 235-240.

Artioli, G., StÅHL, K. \& Hanson, J.C. (1996): Dehydration process in the natural zeolite laumontite, a real-time synchrotron X-ray powder diffraction study. Mater. Sci. Forum 228-231, 369-374.

Atou, T. \& Badding, J.V. (1995): A high resolution laboratory-based high pressure $\mathrm{x}$-ray diffraction system. Rev. Sci. Instrum. 66, 4496-4500.

Avrami, M.L. (1941): Granulation, phase change, and microstructure; kinetics of phase change. III. J. Chem. Phys. 9, 177-184.

BARUCHEL, J. (1993): Neutron and Synchrotron Radiation for Condensed Matter Studies. I. Theory, Instruments and Methods Springer-Verlag, Paris, France.

BenNing, L.G. \& BARNES, H.L. (1998): In situ determination of the stability of iron monosulphides and kinetics of pyrite formation. Mineral. Mag. 62A, 151-152.

WILKIN, R.T. \& BARNES, H.L. (2000): In-situ determination of the stability of iron monosulfides and kinetics of pyrite formation. Chem. Geol. (in press).

BERNER, R.A. (1970): Sedimentary pyrite formation. Am. J. Sci. 268, 1-23.

Bourgeois, D., Ursby, T., WulfF, M., Pradervand, C., Legrand, A., Schildkamp, W., Laboure, S., Srajer, V., Teng, T.Y., Roth, M. \& Moffat, K. (1996): Feasibility and realization of single-pulse laue diffraction on macromolecular crystals at ESRF. J. Synch. Rad. 3, 65-74.

Breck, D.W. (1984): Zeolite Molecular Sieves. Krieger, Malabar, Florida.

Cahill, C.L., Benning, L.G., Norby, P., Clark, S.M., Schoonen, M.A.A. \& PARISE, J.B. (1998a): In-situ X-ray 
diffraction apparatus and its application to hydrothermal reactions of iron sulfide growth and phase transformations. Mineral. Mag. 62A, 267-268.

BARnes, H.L. \& PARISE, J.B. (2000): Insitu, time-resolved $\mathrm{X}$-ray diffraction of iron sulfides during hydrothermal pyrite growth. Chem. Geol. 167, 53-63.

Ko, Younghee, Hanson, J.C., Tan, Kemin \& PARISE, J.B. (1998b): Structure of microporous QUIMnGS-1 and in situ studies of its formation using timeresolved synchrotron x-ray powder diffraction. Chem. Mater. 10, 1453-1458.

Chen, Jiuhua, Kikegawa, T., Shimomura, O. \& Iwasaki, H. (1997b): Application of an imaging plate to the large-volume press MAX80 at the photon factory. J. Synch. Rad. 4, 21-27.

, Li, Rui, PARISE, J.B. \& WeIDNER, D.J. (1996): Pressure-induced ordering in $(\mathrm{Ni}, \mathrm{Mg})_{2} \mathrm{SiO}_{4}$ olivine. Am. Mineral. 81, 1519-1522.

PARise, J.B., Li, Rui, Weidner, D.J. \& VAughan, M. (1997a): The imaging plate system interfaced to the large-volume press at beamline X17B1 of the National Synchrotron Light Source. In High Pressure Research in Mineral Physics: Application to Earth and Planetary Sciences (M.H. Manghnani \& T. Yagi, eds.). Terra Scientific, Tokyo, Japan (139-144).

\& WEIDNER, D.J. (1997): X-ray diffraction study of iron partitioning between $\alpha$ and $\gamma$ phases of the $(\mathrm{Mg}, \mathrm{Fe})_{2}$ $\mathrm{SiO}_{4}$ system. Physica A 239, 78-86.

VAughan, M.T., Li, Rui, Parise, J.B., Koleda, C. \& BALdwin, K.J. (1998): Time-resolved diffraction measurements with an imaging plate at high pressure and temperature. Rev. High Press. Sci. Technol. 7, 272-274.

Christensen, A.N., Jensen, T.R., Norby, P. \& Hanson, J.C. (1998): In-situ synchrotron X-ray powder diffraction studies of crystallization of microporous aluminophosphates and $\mathrm{Me}^{2+}$-substituted aluminophosphates. Chem. Mater. 10, 1688-1693.

Clark, S.M., Evans, J.S.O., O’Hare, D., Nuttall, C.J. \& Wong, Heng-Vee (1994): Real-time in situ X-ray diffraction of intercalation reactions. J. Chem. Soc., Chem Commun., 809-810.

Coppens, P., ed. (1992): Synchrotron Radiation Crystallography. Academic Press, London, U.K.

Cox, D.E. (1992): High resolution powder diffraction and structure determination. In Synchrotron Radiation Crystallography (P. Coppens, ed.). Academic Press, London, U.K. (186-254).

Toвy, B.H. \& EdDy, M.M. (1988): Acquisition of powder diffraction data with synchrotron radiation. Aust. J. Phys. 41, 117-131.
\& Wilkinson, A.P. (1994): Powder diffraction studies using anomalous dispersion. In Resonant Anomalous X-Ray Scattering; Theory and Applications (G. Materlink, C.J. Sparks \& K. Fischer, eds.). North Holland, Amsterdam, The Netherlands (195-219).

Cruciani, G., Artioli, G., Gualtieri, A., Ståhl, K. \& Hanson, J.C. (1997): Dehydration dynamics of stilbite using synchrotron X-ray powder diffraction. Am. Mineral. 82, 729-739.

DAVISON, W. (1991): The solubility of iron sulfides in synthetic and natural waters at ambient temperature. Aquat. Sci. 53, 309-329.

DE Moor, P.-P.E.A., BeElen, T.P.M., KomanscheK, B.U., Diat, O. \& VAN SANTEN, R.A. (1997): In situ investigation of SiTPA-MFI crystallization using (ultra-) small- and wideangle X-ray scattering. J. Phys. Chem. B101, 11077-11086.

Drobner, E., Huber, H., WÄchtershäUser, G., Rose, D. \& Stetter, K.O. (1990): Pyrite formation linked with hydrogen evolution under anaerobic conditions. Nature 346, 742744.

ENG, P.J., RIVERS, M., YANG, B.X. \& SChILDKAMP, W. (1995): Micro-focusing $4 \mathrm{keV}$ to $65 \mathrm{keV} \mathrm{X}$-rays with bent Kirkpatrick-Baez mirrors. In X-Ray Microbeam Technology and Applications (W. Yun, ed.). Proc. Soc. Photo-Opt. Instrum. Eng. 2516, 41-51.

Evans, J.S.O., Francis, R.J., O’Hare, D., Price, S.J., Clark, S.M., Gordon, J., NeIld, A. \& TANG, C.C. (1994): An apparatus for the study of the kinetics and mechanism of hydrothermal reactions by in situ energy dispersive X-ray diffraction. Rev. Sci. Inst. 66, 2442-2445.

FINGER, L.W. (1989): Synchrotron powder diffraction. In Modern Powder Diffraction (D.L. Bish \& J.E. Post, eds.). Rev. Mineral. 20, 309-331.

Francis, R.J. \& O'HARE, D. (1998): The kinetics and mechanisms of the crystallization of microporous materials. $J$. Chem. Soc., Dalton Trans., 3133-3148.

Price, S.J., Evans, J.S.O., O’Brien, S., O'Hare, D. \& ClARK, S.M. (1996): Hydrothermal synthesis of microporous tin sulfides studied by real-time in situ energydispersive X-ray diffraction. Chem. Mater. 8, 2102-2108.

Grey, C.P., Poshni, F.I., Gualtieri, A.F., Norby, P., Hanson, J.C. \& CoRBIN, D.R. (1997): Combined MAS NMR and Xray powder diffraction structural characterization of hydrofluorocarbon-134 adsorbed on zeolite NaY: observation of cation migration and strong sorbate-cation interactions. J. Am. Chem. Soc. 119, 1981-1989.

Gualtieri, A., Norby, P., Artioli, G. \& Hanson, J.C. (1997): Kinetics of formation of zeolite Na-A [LTA] from natural kaolinites. Phys. Chem. Minerals 24, 191-199.

, Hanson, J.C. \& HriljaC, J. (1996):

Rietveld refinement using synchrotron X-ray powder dif- 
fraction data collected in transmission geometry using an imaging-plate detector: application to standard $m-\mathrm{ZrO}_{2} . J$. Appl. Crystallogr. 29, 707-713.

Hammersley, A.P., Svensson, S.O., Hanfland, M., Fitch, A.N. \& HÄUSERMANN, D. (1996): Two-dimensional detector software: from real detector to idealized image or twotheta scan. High Press. Res. 14, 235-248.

Hodeau, J.-L., Bordet, P., Anne, M., Prat, A., Fitch, A.N., Dooryhee, E., Vaughan, G. \& Freund, A.K. (1998): Nine-crystal multianalyzer stage for high-resolution powder diffraction between $6 \mathrm{keV}$ and $40 \mathrm{keV}$. In Crystal and Multilayer Optics (A.T. Macrander, D.M. Mills, A.K. Freund \& T. Ishikawa, eds.) Proc. Soc. Photo-Opt. Instrum. Eng. 3448, 353-361.

Hriljac, J.A., Parise, J.B., Kwei, G.H. \& Schwartz, K.B. (1991): The ab initio crystal structure determination of $\mathrm{CuPt}_{3} \mathrm{O}_{6}$ from a combination of synchrotron X-ray and neutron powder diffraction data. J. Phys. Chem. Solids 52, 1273-1279.

Hulbert, S.F. (1969): Models for solid-state reactions in powdered compacts: a review. J. Br. Ceram. Soc. 6, 11-19.

Jensen, T.R., Norby, P. \& Hanson, J.C. (1998): Hydrothermal transformation of microporous lithium zinc phosphates: a kinetic study using in situ synchrotron radiation powder diffraction. Eur. Powder Diffraction Conf. 5, Pts 1 and 2, 2782, p. 414-417.

JePhCoAt, A.P., Finger, L., W. \& Cox, D.E. (1992): High pressure, high resolution synchrotron X- ray powder diffraction with a position-sensitive detector. High Press. Res. 8, 667-676.

KLug, H.P. \& AleXANDER, L.E. (1974): X-ray diffraction procedures for polycrystalline and amorphous materials $\left(2^{\text {nd }}\right.$ ed.). Wiley Interscience, New York, N.Y.

KuHL, G.H. (1987): Crystallization of low-silica faujasite $\left(\mathrm{SiO}_{2} / \mathrm{Al}_{2} \mathrm{O}_{3} \sim 2.0\right)$. Zeolites 7,451 .

KunZ, M., Lindsley, D.H., Xirouchakis, D., Wang, Yanbin \& PARISE, J.B. (1997): Structural investigations along the join $\mathrm{CaTiOSiO}_{4}-\mathrm{CaSnOSiO}_{4}$. Schweiz. Mineral. Petrogr. Mitt. 77, 1-11.

Larson, A.C. \& Von Dreele, R.B. (1986): GSAS Manual. Rep. LAUR86-748, Los Alamos, New Mexico.

Lee, Yonguae, Cahill, C.L., Hanson, J.C., Parise, J.B., Carr, S.W., Myrick, M.L., Preckwinkel, U.V. \& Phillips, J.C. (1998a): Characterization of $\mathrm{K}^{+}$ion exchange into Na-LSX using time-resolved synchrotron X-ray powder diffraction and Rietveld refinement. In Proc. $12^{\text {th }}$ Int. Zeolite Conf. IV (M.M.J. Treacy, B.K. Marcus, M.E. Bisher \& J.B. Higgins, eds.). Materials Research Society, Baltimore, Maryland (2401- 2408).

, CARr, S.W. \& PARISE, J.B. (1998b): Phase transition upon $\mathrm{K}^{+}$ion exchange into Na-low silica $\mathrm{X}$ : combined
NMR and synchrotron x-ray powder diffraction study. Chem. Mater. 10, 2561- 2570.

Lennie, A.R., Redfern, S.A.T., Champness, P.E., Stoddart, C.R., Schofield, P.F. \& VAughan, D.J. (1997): Transformation of mackinawite to greigite: an in situ X-ray powder diffraction and transmission electron microscope study. Am. Mineral. 82, 302-309.

Liang, X., Andrews, J.E. \& De Haseth, J.A. (1996): Resolution of mixture components by target transformation factor analysis and determinant analysis for the selection of targets. Anal. Chem. 68, 378-385.

Mochizuki, T., Sakurai, Y., Shu, D., KuZay, T.M. \& Kitamura, H. (1998): Design of compact absorbers for high-heat-load X-ray undulator beamlines at SPring-8. $J$. Synch. Rad. 5, 1199-1201.

Moffat, K. \& Ren, Z. (1997): Synchrotron radiation applications to macromolecular crystallography. Current Opinion in Structural Biology 7, 689-696.

Mortier, W.J. \& Bosmans, H.J. (1971): Location of univalent cations in synthetic zeolites of the $\mathrm{Y}$ and $\mathrm{X}$ type with varying silicon to aluminum ratio. 1. Hydrated potassium exchanged forms. J. Phys. Chem. 75, 3327-3334.

Neder, R.B., Burghammer, M., Grasl, T. \& Schulz, H. (1996a): Mounting an individual submicrometer sized single crystal. Z. Kristallogr. 211, 365-367.

$\&$ (1996b): Single crystal diffraction by submicrometer sized kaolinite; observation of Bragg reflections and diffuse scattering. $Z$. Kristallogr. 211, 763-765.

\& (1996c): A vacuum chamber for low background diffraction experiments. Z. Kristallogr. 211, 591-593.

NoRby, P. (1996): In-situ time-resolved synchrotron powder diffraction studies of syntheses and chemical reactions. Mat. Sci. Forum 228-231, 147-152.

(1997a): Hydrothermal conversion of zeolites: an insitu synchrotron X-ray powder diffraction Study. J. Am. Chem. Soc. 119, 5215-5221.

(1997b): Synchrotron powder diffraction using imaging plates: crystal structure determination and Rietveld refinement. J. Appl. Crystallogr. 30, 21-30.

, Cahill, C., Koleda, C. \& Parise, J.B. (1998): A reaction cell for in-situ studies of hydrothermal titration. $J$. Appl. Crystallogr. 31, 481-483.

O’Hare, D., Evans, J.S.O., Francis, R.J., Halasyamani, P.S., Norby, P. \& Hanson, J. (1998b): Time-resolved, in-situ $\mathrm{X}$-ray diffraction studies of the hydrothermal syntheses of microporous materials. Microporous Mesoporous Mater. 21, 253-262. 
Price, S. \& O'Brien, S.

(1998a): The use of in-situ powder diffraction in the study of intercalation and hydrothermal reaction kinetics. Eur. Powder Diffraction Conf. 5, Pts. 1 and 2, 278-2, p. 367-378.

Olson, D.H. \& SHERRY, H.S. (1968): An X-ray study of strontium-sodium ion exchange in Linde $\mathrm{X}$ : an example of a two-phase zeolite system. J. Phys. Chem. 72, 4095-4104.

PARISE, J.B. (1998): New opportunities for microcrystalline and powder diffractometry at synchrotron sources. Synchrotron X-Ray Methods in Clay Science (D.G. Schulze, J.W. Stuki \& P.M. Bertsch, eds.). Clay Mineral Soc., Workshop Lectures 9, 115-145.

\& CHEN, J. (1997): Studies of crystalline solids at high pressure and temperature using the DIA multi-anvil apparatus. Eur. J. Sol. St. Inorg. Chem. 34, 809-821.

Schoonen, M.A.A. \& LAmble, G. (1990): An extended X-ray absorption fine structure (EXAFS) spectroscopic study of amorphous FeS. Geol. Soc. Am., Abstr. Program 22, A293.

TAN, K., Norby, P., Ko, Y. \& Cahill, C. (1997): Examples of hydrothermal titration and real time X-ray diffraction in the synthesis of open frameworks. In Solid State Chemistry of Inorganic Materials (P. Davies, A. Jackobson, C.T. Toradri \& T. Vanderah, eds.). Materials Research Society Proc. 453, 103-114.

Weidner, D.J., Chen, J., Liebermann, R.C. \& CHEN, G. (1998): In situ studies of the properties of materials under high-pressure and temperature conditions using multi-anvil apparatus and synchrotron X-rays. Annu. Rev. Mater. Sci. 28, 349-374.

RICKARD, D. (1989): Experimental concentration-time curves for the iron(II) sulphide precipitation process in aqueous solutions and their interpretation. Chem. Geol. 78, 315-324.

(1995): Kinetics of FeS precipitation. I. Competing reaction mechanisms. Geochim. Cosmochim. Acta 59, 4367-4379.

(1997): Kinetics of pyrite formation by the $\mathrm{H}_{2} \mathrm{~S}$ oxidation of iron(II) monosulfide in aqueous solutions between 25 and $125^{\circ} \mathrm{C}$ : the rate equation. Geochim. Cosmochim. Acta 61, 115- 134.

RiETVELD, H.M. (1969): A profile refinement method for nuclear and magnetic structures. J. Appl. Crystallogr. 2, 65-71.

Rindby, A., Engstrom, P. \& Janssens, K. (1997): The use of a scanning X-ray microprobe for simultaneous XRF/XRD studies of fly-ash particles. J. Synch. Rad. 4, 228-235.

SCHOONEN, M.A.A. \& BARNES, H.L. (1991): Reactions forming pyrite and marcasite from solution. I. Nucleation of $\mathrm{FeS}_{2}$ below $100^{\circ}$ C. Geochim. Cosmochim. Acta 55, 1495-1504.

Shaw, S., Clark, S.M. \& Henderson, C.M.B. (2000a): Hydrothermal formation of the calcium silicate hydrates tobermorite $\left(\mathrm{Ca}_{5} \mathrm{Si}_{6} \mathrm{O}_{16}(\mathrm{OH})_{2} \bullet 4 \mathrm{H}_{2} \mathrm{O}\right)$ and xonotlite $\left(\mathrm{Ca}_{6} \mathrm{Si}_{6} \mathrm{O}\right.$
$\left.(\mathrm{OH})_{2}\right)$ : an in-situ synchrotron study. Chem Geol. 167, 129140 .

, WANG, Y., Henderson, C.M.B., CAHILl, C.L., Parise, J.B., Benning, L., Rivers, M. \& Shen, G. (1998): In-situ hydrothermal synthesis using 13 BM-D at the APS. Central Laboratory of the Research Council, Daresbury Laboratory, Tech. Rep. DL-TR-98-002.

Rivers, M. \& SHEN, G. (2000b): Extending in-situ hydrothermal experiments at the SRS, Daresbury to higher temperatures at the APS, Argonne. Chem Geol. (in press).

Henderson, C.M.B. \& Komanschek, B.U. (2000c): Dehydration/recrystallization mechanisms, energetics, and kinetics of hydrated calcium silicate minerals: an in-situ TGA/DSC and synchrotron radiation SAXS/ WAXS study. Chem. Geol. 167, 141-159.

SHERRY, H.S. (1968): The ion-exchange properties of zeolites. IV. Alkaline earth ion exchange in the synthetic zeolite Linde X and Y. J. Phys. Chem. 72, 4086-4094.

Shimomura, O., Yamaoka, S., Yagi, T., Wakatsuki, M., Tsuji, K., Kawamura, H., Hamaya, N., Aoki, K. \& AкIMOTo, S. (1985): Multi-anvil type X-ray system for synchrotron radiation. In Solid State Physics Under Pressure: Recent Advances with Anvil Devices (S. Minomura, ed.). KTK Sci. Publ., Tokyo, Japan (351-356).

Shu, D., Brite, C., Nian, T., Yun, W., Haeffner, D.R., Alp, E.E., Ryding, D., Collins, J., Li, Y. \& Kuzay, T.M. (1995): Precision white-beam slit design for high powerdensity $\mathrm{x}$-ray undulator beamlines at the advanced photon source. Rev. Sci. Instrum. 66, 1789-1791.

Siddons, D.P., Furenlid, L., Pietraski, P., Yin, Z., Li, Z., Smith, G., Yu, B. \& Harlow, R. (1999): Instrumentation developments for X-ray powder diffraction at Brookhaven. Synch. Rad. News 12(4), 21-26.

Yin, Z., Furenlid, L., Pietraski, P., Li, Z. \& HARLOW, R. (1998): Multichannel analyzer/detector system for high-speed high-resolution powder diffraction. In Crystal and Multilayer Optics (A.T. Macrander, D.M. Mills, A.K. Freund \& T. Ishikawa, eds.). Proc. Soc. PhotoOpt. Instrum. Eng. 3448, 120-131.

Smith, G.C. (1991): X-ray imaging with gas proportional detectors. Synch. Rad. News 4, 24-30.

StÅHl, K., Artioli, G. \& Hanson, J.C. (1996): The dehydration process in the zeolite laumontite: a real-time synchrotron X-ray powder diffraction study. Phys. Chem. Minerals 23, 328-336.

Svensson, S.O., BIRCh, J., Müller, H. \& Kvick, Å. (1997): Time-resolved X-ray powder diffraction using a large-area CCD-based detector and Rietveld refinement: solid-state polymerization of $\mathrm{S}_{2} \mathrm{~N}_{2}$ to $(\mathrm{SN})_{\mathrm{x}}$. J. Synch. Rad. 4, 83-94.

TAYlor, P., Rummery, T.E. \& Owen, D.G. (1979): On the conversion of mackinawite to greigite. J. Inorg. Nucl. Chem. 41, 595-596. 
Thoms, M., Bauchau, S., Häusermann, D., Kunz, M., Le Bihan, T., Mezouar, M. \& Strawbridge, D. (1998): An improved X-ray detector for use at synchrotrons. Nucl. Instrum. Methods Phys. Res. A413, 175-184.

Toraya, H., Hibino, H. \& Ohsumi, K. (1996): A new powder diffractometer for synchrotron radiation with a multipledetector system. J. Synch. Rad. 3, 75-83.

, Takata, M., Hibino, H., Yoshino, J. \& OHsumi, K. (1995): Long horizontal parallel slits with 0.03-degrees angular resolution for powder diffraction using synchrotron-radiation. J. Synch. Rad. 2, 143-147.

WÄCHTERSHÄUSER, G. (1988): Pyrite formation - the first energy source for life: a hypothesis. System Appl. Microbiol. 10, 207-210.

Weidner, D.J. \& MaO, H.-K. (1993): Photons at high pressure. NSLS Newsletter March, 1-15.

Wilkin, R.T. \& BARNES, H.L. (1996): Pyrite formation by reactions of iron monosulfides with dissolved inorganic and organic sulfur species. Geochim. Cosmochim. Acta 60, $4167-4179$
WulfF, M., Schotte, F., NAYlor, G., Bourgeois, D., Moffat, K. \& Mourou, G. (1997): Time- resolved structures of macromolecules at the ESRF: single-pulse Laue diffraction, stroboscopic data collection and femtosecond flash photolysis. Nucl. Instrum. Methods Phys. Res. A398(1), 6984.

Yang, Xiaojing, Ren, Zhong \& Moffat, K. (1998): Structure refinement against synchrotron Laue data: strategies for data collection and reduction. Acta Crystallogr. D54, $367-$ 377.

Young, R.A. (1995): The Rietveld Method. Oxford University Press, New York. N.Y.

Zhao, Y., Von Dreele, R., Shankland, T., Weidner, D., Zhang, J., WANG, Y. \& GASPARIK, T. (1997): Thermoelastic equation of state of jadeite $\mathrm{NaAlSi}_{2} \mathrm{O}_{6}$ : an energydispersive Rietveld refinement study of low symmetry and multiple phases diffraction. Geophys. Res. Lett. 24, 5-8.

Received September 1, 1999, revised manuscript accepted July 8, 2000. 